\title{
Let's talk: How communication affects contract design
}

\author{
Jordi Brandts, Gary Charness, and Matthew Ellman
}

June, 2012

\begin{abstract}
We study experimentally how the ability to communicate affects the frequency and effectiveness of flexible and inflexible contracts in a bilateral trade context where sellers can adjust trade quality after observing a post-contractual cost shock and a discretionary buyer transfer. In the absence of communication, we find that rigid contracts are more frequent and lead to higher earnings for both buyer and seller. By contrast, in the presence of communication, flexible contracts are much more frequent and considerably more productive, both for buyers and sellers. Also, both buyer and seller earn considerably more from flexible with communication than rigid without communication. Our results show quite strongly that communication, a normal feature in contracting, can remove the potential cost of flexibility (disagreements caused by conflicting perceptions). We offer an explanation based on social norms.
\end{abstract}

Keywords: Communication, contracts, perceptions and cooperation.

JEL codes: C91, D03, D63, J41, D86

\footnotetext{
* Brandts: Universitat Autònoma de Barcelona, Institut d'Anàlisi Econòmica (CSIC) and Barcelona GSE. Charness: University of California, Santa Barbara. Ellman: Institut d'Anàlisi Econòmica (CSIC) and Barcelona GSE. The authors thank Christina Rott for excellent research assistance and Hector Solaz for running the experiments for us at the LINEEX lab of the University of Valencia. The authors benefited from comments received at the following conference and seminar presentations: IMEBE in Barcelona, ESA in Chicago, CESIfo in Munich, ASSA in Chicago, USC Law School, University of Amsterdam, University of Rennes, Maastricht University and Paris I, as well as from Florian Englmaier, Oliver Hart, Bentley MacLeod, Pedro Ortín, Pedro Rey-Biel, Arno Riedl, Joel Sobel, and Christian Zehnder. Brandts acknowledges financial support from the Antoni Serra Ramoneda (UAB - Catalunya Caixa) Research Chair, the Spanish Ministry of Economics and Competitiveness (Grant: ECO2011-29847-C02-01) and the Generalitat de Catalunya (Grant: 2009 SGR 820) and Ellman gratefully acknowledges financial support from the Spanish Ministry of Economics and Competitiveness (Grant: ECO2011-25293) and the Generalitat de Catalunya (Grant: 2009 SGR 820).
} 


\section{Introduction}

An enduring topic in contract theory is how to motivate the seller of a good to provide high quality when the seller has discretion over quality after agreement on trade. Formal (courtenforced) contracts can generate quality incentives by fixing rewards and punishments, but formal contracting is usually imperfect and costly. So trading parties often rely heavily on informal procedures and industry norms (see Macauley, 1963). Traders' subjective perceptions then directly determine how they enforce their (informal) agreements. A clear "mutual understanding of the events that determine contract breach" (MacLeod, 2007) becomes a key factor behind successful trading relationships. Communication has a vital role to play.

Business practitioners encourage interacting parties to simplify their plans where communication is difficult. Simple plans are less responsive to events but they limit the risk of misunderstandings and disagreements. We develop these ideas formally to investigate their implications for contract design and the impact of communication. We test our novel predictions in a simple new experimental context. Our results support the notion that without communication, flexible (responsive) plans can lead to problems and inefficiencies, but that matters are strikingly different in a free-communication environment. Communication leads to a dramatic increase in prices and quality and a dramatic decrease in rejections of proposed contracts, with both contracting parties earning considerably more.

We work in a trade context where adaptation is valuable but potentially problematic. A buyer and a seller interact once (see MacLeod, 2007, on the parallels between repeated game and behavioral enforcement of informal agreements). They both observe a non-verifiable shock to the seller's cost but only after they commit to joint trade at some base price. The buyer can potentially respond to the shock with an additional transfer before the seller sets the trade's non- 
verifiable quality (superior, neutral or inferior), but the simplest plan is trade at a fixed price. A "rigid contract" commits to such a plan: it fixes a base price and rules out discretion to make additional transfers later on (see design section for interpretation). By contrast, a "flexible contract" permits the buyer to set an additional transfer after observing the cost shock. We investigate whether traders choose rigid or flexible contracts and how quality and profitability are affected in settings with and without ongoing, free-form, bilateral communication.

In principle, flexibility is preferable. The buyer can use it to raise joint surplus by adapting the transfer to share in the seller's cost (this insures the seller, reduces inequality and quite possibly encourages seller cooperation). Utility is transferable and rigidity only commits the buyer against being more generous, so one might expect traders to negotiate a flexible agreement. However, flexibility can have a downside. It leaves more room for ongoing disagreement over appropriate actions. Such disagreements are often costly, because disgruntled sellers tend to set inefficiently low quality.

A rigid contract completely pins down the buyer's transfer obligation. So the norm of "living with the consequences of one's choices" (see Hayek's decision responsibility formulation below) admonishes a seller who accepts a rigid contract from later feeling cheated by the agreed transfer level. By contrast, the flexible contract (absent communication) leaves the transfer plan partially open and this leaves much room for disagreement ex post over the additional transfers that the buyer should pay in each cost state. Accordingly, without communication we expect traders to select rigid contracting in settings where seller discretion over quality makes such disagreements particularly costly.

Rich communication radically changes this prediction. Intuitively, we expect traders with symmetric information to use communication to avoid costly disagreements. Traders can 
agree on a flexible contract with informal (not court-enforced) commitments to a unique additional transfer specified for each cost state (by the buyer) and to high quality (by the seller). Such agreements are unambiguous: they specify exactly what each trader should do in each state, so they leave no room for subsequent disagreements. Communication removes the downside of flexibility by clarifying the buyer's transfer plan. ${ }^{1}$ We therefore predict that a communication channel (open during initial negotiations) will lead traders to shift from rigid to flexible contracting. In essence, communication reduces the need for simple plans and therefore complements flexibility.

Our results strongly confirm these predictions. In our baseline no-communication treatment, we find higher prices, quality and profitability for rigid than flexible contracts. Buyers (who always propose the contract type) earn 22 percent more overall with rigid contracts than with flexible contracts, seller earnings are essentially unaffected, overall total earnings are 11 percent higher, and traders choose rigid contracts 25 percent more frequently than flexible ones. The results are quite different in our communication treatment: Buyers earn 34 percent more with flexible contracts than with rigid contracts, sellers earn 26 percent more, overall profits are 30 percent higher, and traders choose flexible thrice as often as rigid; indeed, the proportion of flexible contracts grows over time, reaching 84 percent.

In addition, we find that overall (not controlling for contract type) buyers earn 54 percent more in the communication treatment, sellers earn 167 percent more (the price paid is 130 percent higher with communication and rejections become very rare), and total earnings more than double. These results are fully consistent with the clarification role of communication

\footnotetext{
${ }^{1}$ Of course, the buyer (and seller) might breach the informal terms of the agreement, but lowering promised additional transfers limits this risk. So flexible contracting is optimal even when trustworthiness is limited. In our game, the seller's breach temptation (the cost of superior quality) is low and the buyer has a strong incentive to fulfill her transfer commitments to avoid seller retaliation (inferior quality).
} 
discussed above. In addition, communication permits informal quality commitments that can explain some efficiency increase for both contract types; social-preference theories can even explain why communication might complement flexible contracting, however, they cannot explain why rigid should ever predominate (in our base game). To shed further light on how communication works, we code the chat data to analyze which chat categories are most closely associated with the relative success of flexible and rigid contracts. Consistent with our main prediction and these complementary effects, we find that clarification (of transfer plans) is significantly associated with successful outcomes (high total earnings) when flexible contracts are chosen, while friendliness and, less robustly, trust (quality promises) are positively associated with good outcomes in rigid as well as flexible contracts.

This project is related to Hart and Moore's (2008) theory and Fehr, Hart and Zehnder's (2009, 2011A and 2011B) experiments, henceforth denoted HM, FHZb, FHZa and FHZc (where a,b,c reflects the order of writing). Conflicting feelings of entitlement or "reference points" lead to retaliation: the cost of disagreement is inefficiently low quality. ${ }^{2}$ The main difference is that only formal and competitively-determined contracts shift the reference points in HM's theory, while in our view informal (and formal) agreements affect perceived entitlements and they can do so with or without competition. In our framework, communication leads to informal agreements that enable traders to (get around non-contractibility restrictions on formal contracts and still) avoid the costly disagreements otherwise associated with flexible contracts. By contrast, applying HM directly, neither rigidity nor communication has an impact in a noncompetitive setting like ours. In essence, we adapt HM's theory to capture the idea that bilateral agreements can also affect (perceived) entitlements. Our predictions follow from the

\footnotetext{
${ }^{2} \mathrm{HM}$ and FHZa present the psychological phenomena of self-serving beliefs as a critical problem of flexibility, noting that uncertainty in perceived entitlements can generate the same results.
} 
formal model of Hart and Moore (2008) after adapting the process that determines reference points.

Concretely, our results follow from applying the norm of decision responsibility, that people should not feel entitled to get more than the anticipatable consequences of their agreements (whether formal or informal). Without communication, flexible contracts lead to unclear expectations so, unlike rigid contracts, they fail to restrain perceived entitlements. Communication removes this downside because, in our symmetric information, rich language setting, traders can then clarify, discuss and adapt their plans and expectations until mutually compatible (that is, until their reference points coincide). ${ }^{3}$

The remainder of this paper is structured as follows. We review the existing literature in section 2 and present our experimental design and implementation in section 3 . We derive our predictions and experimental design in section 4, and describe experimental results in section 5 . Section 6 offers a discussion of our findings and section 7 concludes.

\section{Related literature}

Non-binding, free-form communication (cheap talk) is ubiquitous in the field environment. Our study introduces a rich message space and we permit a two-way flow of information between the buyer and seller. Communication works in different contexts for different reasons. Cheap talk has been shown to improve cooperation or coordination between two parties. For example, Cooper, DeJong, Forsythe, and Ross (1992) find that non-binding pre-

\footnotetext{
${ }^{3}$ In essence, our communication result represents a much simpler cousin of the Maskin and Tirole (1999) challenge to the Grossman-Hart-Moore "observable but non-verifiable" modeling strategy. Maskin and Tirole (1999) develop mechanisms that make non-verifiability of (mutually) observable payoff-relevant events irrelevant (if renegotiation can be restricted or traders are risk averse), because "message games" (ex post) can induce revelation of these events. Our setting is much simpler and only requires informal agreements (ex ante communication) that specify complete plans of action.
} 
play communication is effective in improving the rate of the Pareto-superior (but riskdominated) outcome. ${ }^{4}$ Charness (2000) shows a very high rate of coordination on the payoffdominant equilibrium in a Stag Hunt, despite the issue of the credibility of the signal, as pointed out in Aumann (1990). More recently, Charness and Dufwenberg (2006) and Charness and Dufwenberg (2011) demonstrate that free-form communication can be very effective in steering behavior towards optimal social outcomes when there is hidden action or hidden information. Promises (statements of intent) are the key driving force in this process, as they help to raise expectations and improve the credibility of the signals. Interestingly, in our study, communication helps by (we argue) avoiding over-expectations, essentially lowering expectations.

Brandts and Cooper (2007) consider Leontief production in a team of four workers. Coordination failure is rife in a no-communication treatment. In a treatment where a manager, assigned to each team, can either increase the incentives of each team member or communicate by sending them free-form messages, analysis of chat content reveals that a simple communication strategy is very effective: specifically, the manager requests high effort and points out the mutual benefits of high effort. The content of effective communication for coordination is quite different from that needed in Charness and Dufwenberg's $(2006,2011)$ principal-agent setting. Yet in both cases, communication helps by clarifying intentions and expected actions and thereby influencing beliefs.

Ellman and Pezanis-Christou (2011) examine how the structure of the decision-making process (horizontal or vertical) and communication affect the extent to which a firm chooses to maximize own profits at the expense of a helpless third party. The communication treatment is

\footnotetext{
${ }^{4}$ For an interesting theoretical analysis of the effects of communication in coordination games see Ellingsen and Östling (2010).
} 
the same as used here and we use a similar content analysis strategy. In the data, communication makes vertical firms more ethical which leads to notably greater social surplus. The authors infer that voice is a form of involvement that leads actors to feel more responsible for group decisions. Here, we argue that communication improves outcomes, because sellers feel responsible for accepting any clearly-stated (formal or informal) agreement.

Without communication, there is some evidence that flexibility has negative consequences. FHZa find that rigid contracts can induce better outcomes for buyers than flexible contracts in an environment with competition between two potential sellers and uncertainty over a potential cost shock. ${ }^{5}$ Their main result is that the buyer's average profit is higher with rigid contracts, because flexible contracts lead to lower quality when controlling for total price. The seller's profit is lower, so total earnings are almost the same. ${ }^{6}$ Rigid contracts are chosen 50 percent of the time. Since rigid contracts preclude trade in their bad state of the world, our environment seems more realistic: field environments generally allow sellers to trade; in particular, sellers can trade at a loss if they consider the contract to be fair on average.

FHZb seek to verify that competition between sellers is the driving force behind FHZa's result. To create a control that eliminates competition between sellers, they impose base prices (randomly selected from the winning seller bids of the competitive treatment) onto the buyer and sellers. Their main result is that rigid contracts are no longer better for the buyers (though the rigid contract is now chosen 82 percent of the time). Buyer profits are now slightly (but not

\footnotetext{
${ }^{5}$ Two potential buyers are matched with two potential sellers (with random re-matching for 15 periods). Each seller has two units to sell and each buyer can purchase at most one unit. The buyer determines the type of contract (rigid or flexible) and the two sellers compete over price (tied within an exogenous interval to prevent loss-making trades). The state of nature (seller cost shock) is then determined. With a flexible contract, the buyer can then adjust by unilaterally increasing the price to be paid (subject to a no-loss upper bound). After learning the final price, the seller trades if the price covers cost; to simplify, the seller does not actually choose here but this assumption captures the "at will" nature of their contracting environment. If trading, the seller then chooses a quality level from normal or low (sabotage). Choosing low/sabotage is costly to the seller, but is much more costly to the buyer.

${ }^{6}$ In our no-chat treatment, we find that rigid contracts yield higher earnings for sellers as well as buyers (see below).
} 
significantly) lower with rigid contracts and contract type does not affect quality. Notice that our norm of decision responsibility does not apply to the initial contract here, because FHZb's design has no prior agreements; sellers are not responsible for the price, since it is imposed on them (as opposed to determined by seller bidding as in FHZa).

FHZc, a recent study conducted independently from ours, does consider a limited form of communication (buyers must send two numbers indicating state-contingent promised transfers before sellers compete). ${ }^{7}$ In this variation on FHZa, flexible contracts are no worse than rigid ones, however, flexible contracts are still no more profitable than rigid ones. By contrast, in our setting, communication makes flexible contracts sharply more profitable. One explanation for this difference is that free-form communication is much more effective than restricted and unilateral communication. Indeed, a stylized fact emerging from the experimental literature on communication is that simple, exogenous messages are not effective for avoiding inefficient equilibria when these are unique (though they are often effective for equilibrium selection when there are multiple equilibria). ${ }^{8}$ Additionally, our bilateral communication is more personal and reinforces seller responsibility, whereas the buyer's numerical promises in FHZc are unilateral and directed at both the sellers. ${ }^{9}$

Erlei and Reinhold (2011) note that in FHZa sellers have reason to blame buyers for selecting rigid contracts given that total price is then driven down to a minimum by competition between sellers. They argue that this may affect sellers' behavior independent of reference points. So they investigate the case of exogenous contract types, finding that quality is higher for

\footnotetext{
${ }^{7} \mathrm{FHZc}$ and our study were conducted independently and roughly contemporaneously.

${ }^{8}$ Examples include Charness (2000), Andreoni (2005), Charness and Dufwenberg (2010), Ben-Ner, Putterman, and Ren (2011), and Oprea, Charness, and Friedman (2012).

${ }^{9}$ The competition in FHZc may also explain the weaker effect. HM's competition-based theory predicts that communication will not resolve the disagreement cost of flexibility to the extent that communication interferes with the impersonal objectivity of competition; in FHZc, each buyer personally controls his or her informal commitments - competitive bidding (by sellers) only fixes the base price. In some settings, competition might also affect the credibility of communication.
} 
both contract types. They interpret this in terms of negative reciprocity when rigid contracts are chosen and (fairness) signaling when flexible contracts are chosen. ${ }^{10}$ Notice, however, that choosing rigid is not necessarily unkind or unfair in our noncompetitive setting because here the buyer can readily compensate (for precluding additional transfers) by setting an arbitrarily high base price.

In sum, the existing literature on flexible contracts versus inflexible ones provides some support for the notion that ex ante flexibility can lead to ex post misunderstandings in a specific context. Our study generalizes into new trade and contract environments and, most importantly, argues that the picture painted is substantially less gloomy than previously reported.

\section{Experimental design and implementation}

Our focus is on communication and agreements. Communication is possible in most realworld settings and is typically free-form and personalized. Our no-chat treatment starkly prevents all communication, but we intend it to capture a setting in which traders cannot reach a common understanding on the precise terms of trade because the relevant trade contingencies are complicated and difficult to describe in the time available.

Before describing our design in detail, we motivate three other major design choices. We chose to study bilateral negotiation (no competition), "specific performance" contracting (that is, contracts that always enforce trade), and to allow for costly quality as well as costly sabotage (that is, what one might call "shining" as well as what HM call "shading"). Since our predictions

\footnotetext{
${ }^{10}$ They also offer a replication treatment of FHZa's endogenous contract type setting. They find notably more low quality than in FHZa (particularly for rigid) and buyers reveal a preference for flexible contracts (chosen 72.3 percent of the time) in contrast to the indifference found in FHZa. At the same time, buyer payoffs are again higher for rigid, though not significantly so.
} 
do not rely on competition, it is natural to dispense with it. ${ }^{11}$ Doing so allows us to focus on a simpler environment and reduces the risk of subjects becoming confused. The control study of FHZb also removes competitive bidding, but has no price negotiation at all: prices and contracts are imposed on the seller (and the buyer only chooses the contract type); so our bilateral negotiation setting is sharply different. Specific performance contracting also keeps the trading problem simple: trade is decided once and for all ex ante (stages 1 and 2). This simplicity is quite valuable. In "at will" contracting environments, as in FHZa,b,c, traders face an ex post trade decision as well. To simplify, FHZa,b,c restrict this ex post trade decision by imposing that trade can only occur when ex post individually rational. However, traders clearly deviate from purely selfish motives in their game, and might wish to do so in the trade decision itself. Finally, costly (higher) quality is the more standard assumption in economics. We allow for both upward and downward deviations from the self-interested benchmark decision (neutral quality). This adds realism and identification power; it slightly raises complexity but the previous two design features (and our help screen described below) seem to more than compensate. ${ }^{12}$

Participants play the same one-shot basic game in each of 11 periods (the first period is a trial run and does not affect actual payments). ${ }^{13}$ Across periods, they are re-matched and no two subjects ever play each other more than once nor observe another's past choices, so there is no opportunity for building a personal reputation. Since the same game is played independently in each period, we can focus our analysis on the basic game, bearing in mind that subjects may

\footnotetext{
${ }^{11}$ We agree with HM's insight that competitive processes can reveal external information and shift views about appropriate shares. However, we believe that simple bilateral agreements alone can have powerful effects on people's views about what is appropriate; their agreements shift their perceived obligations and entitlements.

${ }^{12}$ Overall, our simple context encouraged us to make a minor design difference compared to FHZa,b,c: we do not provide any feedback on payoffs in other buyer-seller matches (FHZa,b,c inform buyers of the running averages of buyer payoffs for each contract type and contract type popularity).

${ }^{13}$ Business relationships between two firms or a firm and an employee are typically repeated over time, but the oneshot model is often relevant when the buyer is a final consumer (see the construction examples in Hart, 1995). In any case, the one-shot setting provides an important benchmark before moving on to analyze repeated interactions.
} 
learn how to play across periods.

\subsection{Details and parameters of the basic game}

After a buyer and a seller have been matched, the buyer chooses a contract type (rigid or flexible) and a price $\mathrm{P}$ to offer to the seller (or makes no offer). The seller then accepts or rejects the offer. If no contract is agreed, the buyer and seller each receive outside option payments (5 each). If the seller accepts a contract offer, the seller has to provide a good (or service) to the buyer. The seller's basic cost $\mathrm{C}$ is subject to a shock; $\mathrm{C}$ is either 0 or 20 with a 50 percent probability of each outcome. We chose this relatively large cost shock to make it salient. Both buyer and seller observe the outcome of this cost shock. If a rigid contract was chosen at the initial contracting stage, the price cannot now be changed and remains at the initial level of $\mathrm{P} .{ }^{14}$ However, if a flexible contract was chosen, the buyer can now augment the initial price of $\mathrm{P}$ by any amount, which we denote by Q. After observing the cost shock and any additional transfer Q from the buyer, the seller chooses the quality of the good.

We denote this quality response by $x$, which can take three values: $x=0$ represents normal quality and involves no additional cost, $x=-1$ represents an inferior quality, and $x=+1$ represents superior quality. Either non-zero $x$ costs the seller one unit on top of the base cost C. Implicitly, the stage-0 trade contract gives the seller an incentive to provide a base quality good (i.e. to set $x=0$ ) and any deviation, upwards or downwards, from this quality level is costly. ${ }^{15}$ Both upward and downward marginal deviations have minor cost implications for the seller, but first-order implications for the buyer. Concretely, the buyer's payoff from the good increases with quality $x$ from $10(x=-1)$ to $30(x=0)$ to $45(x=1)$. This captures a natural decreasing

\footnotetext{
${ }^{14}$ In practise, such rigidity is more likely enforced by informal commitments, but we simplify (so do FHZa,b,c).

${ }^{15}$ The seller's cost of $x=+1$ represents a cost of increasing quality mitigated by any quality rewards (contractual or reputational); the seller's cost of $x=-1$ can represent a cost of hidden sabotage (careful distortions to satisfy the letter of the contract) or a cost from loss of reputation or rewards, mitigated by any effort reduction.
} 
marginal return on quality: the buyer's gain from raising $x$ to 0 (from inferior to basic) is higher, at 20, than the buyer's gain of 15 from raising $x$ to 1 (from basic to superior). These large gains in buyer value at low seller cost give buyers a strong incentive to seek to induce sellers to choose high quality (despite the one-shot setting).

In sum, the monetary earnings of buyer, $\Pi_{\mathrm{B}}$, and seller, $\Pi_{\mathrm{S}}$, are five each if no contract is agreed upon and otherwise $\Pi_{\mathrm{B}}=5+\mathrm{v}(x)-\mathrm{P}-\mathrm{Q}$ for the buyer and $\Pi_{\mathrm{S}}=5+\mathrm{P}+\mathrm{Q}-\mathrm{C}-x$ for the seller, where the buyer's trade value, $\mathrm{v}(x)$ equals 10,30 , or 45 , depending on the value of $x$. The instructions are presented in Appendix A.

\subsection{Timing}

The exact sequence of events is defined by the following five-stage game in which both parties always learn what happened in all preceding stages:

Stage 1: Buyer B chooses whether to offer the seller $S$ a rigid or flexible contract; in each case, the buyer sets the contract's initial price offer $P$.

Stage 2: Seller S accepts or rejects this offer.

Stage 3: The computer randomly determines the seller's base cost C (at 0 or 20 with 50 percent probability for each)

Stage 4: If the contract is flexible, buyer B sets an additional transfer $Q$.

Stage 5: Seller S sets the quality level, $x=-1, x=0$ or $x=1$.

In the communication (or "chat") treatment, we introduce free-form communication to allow traders to make informal agreements. Our interest is three-fold. We examine whether people use communication to establish informal contracts, we characterize the discussions that lead to any such informal contracts, and we investigate how these affect behavior.

The buyer and seller can send each other written messages through a chat window on the 
help-screen. They can send such messages at any time during a period, starting from the moment a buyer and a seller are matched and begin negotiating right up until the seller sets $x$ in the final stage (stage 5).

\subsection{Implementation}

Our sessions were conducted in Valencia at the LINEEX laboratory. Each session involved groups of 22 people who played 10 periods (and one practice period); no one could participate in more than one session. One of the 10 non-practice periods was randomly selected for payment. Each payoff unit was worth one euro $(1 €)$, and participants received an $8 €$ show-up fee on top of their earnings.

Each participant's role (buyer or seller) was fixed for the duration of the session and (in the payoff periods) no participant was ever matched twice with any other participant; this was all common information. Instructions and a careful explanation were read aloud at the start of each session. A help screen, always immediately available, enabled each person to compute (privately) the payoff implications for self and current partner of any set of choices he or she wishes to consider. There were four sessions without communication and four sessions with communication (chat) between the buyer and the seller. Thus, in all we had 176 participants in our experiment. Average earnings were approximately $17 €$ for no-chat sessions that lasted about 90 minutes, and $25 €$ for the chat sessions that lasted about 120 minutes.

\section{Our predictions}

We start with some general considerations about the interaction between buyers and sellers. In section 4.2 we present our theoretical predictions for the choice between rigid and flexible contracts, in section 4.3 we make predictions on earnings levels and in section 4.4 we 
discuss the predictions on the role of certain chat categories.

\subsection{Transfers and quality levels (general considerations)}

If the buyer (she) and seller (he) are rational, self-interested maximizers, the seller always minimizes cost and the buyer minimizes additional transfers after setting the base price $\mathrm{P}$ to just secure seller acceptance. ${ }^{16}$ This outcome is independent of the choice between rigid and flexible contracts. Communication has no effect either.

Previous evidence from ultimatum-game experiments suggests that this prediction will not be prominent in the data. The above buyer strategy leaves the seller no share of the surplus, so the seller would (as in the ultimatum game) often reject the proposal or retaliate with inferior quality $(x=-1)$, which yields the buyer a payoff of 5 (her outside option) or even less (in the case with a risk premium and retaliation). Moreover, a mass of experimental evidence leads us to expect higher quality and social surplus in many encounters. The key factors permitting higher quality are pro-sociality (altruism and efficiency concerns), trust and reciprocation (e.g., from inequality aversion or social norms). Notice that the expected material surpluses from trades with quality $x=-1,0,1$ are $9,30,44$, respectively, while the alternative trade surplus (sum of outside options) is 10 .

Altruism and efficiency concerns clearly raise the levels of transfers and qualities (see Andreoni, 1990, and Charness and Rabin, 2002). Trust also raises quality and transfers, because sellers can then commit to higher quality in return for higher transfers. Contingent prosociality can also generate such reciprocation (sellers being better-disposed towards buyers who pay high transfers). Finally, inequality-aversion and norms of fairness can generate reciprocation (as of

\footnotetext{
${ }^{16}$ So $x=\mathrm{Q}=0$ and $\mathrm{P}=10+\mathrm{RP}$ for some risk premium $(\mathrm{RP})$ between 0 and 10 ; even at $\mathrm{RP}=10$, buyer earnings exceed the buyer's alternative payoff: $\Pi_{B}=5+v(0)-20=15>5$.
} 
course can models of intrinsic reciprocity, see Sobel, 2005); see the models of Fehr and Schmidt (1999) or Bolton and Ockenfels (2000). ${ }^{17}$ Any such expected reciprocation gives the buyer an incentive to raise transfers ( $\mathrm{P}$ and/or Q). High quality becomes likely if the buyer can reasonably estimate the seller's corresponding threshold transfer (as is plausible in the chat treatment). All three perspectives predict a correlation between the total transfer and quality ( $\mathrm{T}$ and $x)$, both being higher with prosociality, trust and (accurately-anticipated) reciprocation. ${ }^{18}$

\subsubsection{Cost sharing (or how transfers vary with the cost state)}

Cost sharing is only feasible with a flexible contract and is usually then both credible and attractive. A self-interested buyer is motivated to share in the seller's cost if the seller is inequality averse (or internalizes a sharing norm). Seller risk aversion also induces buyers to share if prosocial or if self-interested but able to negotiate informal insurance agreements. The latter requires communication. The agreements are then credible since the seller's cost of fulfilling quality promises is very low and the buyer has strong incentives to fulfill promises when seller quality promises are conditional on buyer fulfillment.

In the chat treatment, the social norm of equal sharing may suggest setting $\mathrm{P}=23$ with $\mathrm{Q}$ $=0$ in the low $\operatorname{cost}(C=0)$ and $Q=10$ in the high $\operatorname{cost}(C=20)$ states. So, defining $d Q=Q(20)$ $\mathrm{Q}(0)$, we might expect $\mathrm{dQ}=10$ as the modal sharing outcome. We also might expect some dQ in $[0,10)$ as a result of under-trading in insurance or if traders think the seller should bear more of the cost burden since it falls directly on the seller. Finally, dQ in $(10,20]$ is possible if the seller is more risk averse than the buyer.

\footnotetext{
${ }^{17}$ Aversion to other-favoring inequality (i.e., the other party having a higher material payoff) can explain retaliation $(x \leq 0)$. Seller aversion to self-favoring inequality can generate $x>0$; e.g., after $\mathrm{C}=20$ and total transfer $\mathrm{T}=33$, the seller may prefer $x=1$ over $x=0$ to give the more equal buyer-seller payoff pair of $(17,17)$ instead of $(2,18)$.

18 These effects are also mutually reinforcing; for instance, when trust or prosociality raise quality, inequality aversion leads to increased transfers.
} 
In the no-chat treatment, we predict less cost sharing for three reasons. First, traders cannot negotiate reduced average transfers in return for insurance and there is less trust to support any tacit insurance agreement. Second, buyers may raise $Q(0)$ in the fear that selfserving sellers will always demand some additional transfer. Third, social motivations for sharing are lower (see 4.2.1). So we predict dQ will be lower without chat.

\subsection{Communication and the choice between rigid and flexible contracts}

It is not obvious why buyers should ever pick rigid contracts. Rigidity is a commitment against paying an additional transfer later on. This has no clear strategic advantage (it can only lower the seller's material payoff and raise the risk of inciting rejection or low quality). However, a rigid contract has the advantage of simplicity. Once the seller accepts a rigid contract, there is no room for later disagreement over what the buyer should do. By contrast, a flexible contract leaves the buyer with discretion over the additional transfer Q.

This intuitive idea is formalized for settings with seller competition in HM. In their formulation, a reciprocal seller sets low quality if the buyer transfers less than a threshold value determined by the seller's reference point (or sense of seller entitlement). They posit that a competitively-determined contract price pins down this reference point, justifying that traders tend to accept the objectivity of a competitive process. In HM and FHZa, competition determines the base price and hence the final price in rigid contracts, but not in flexible contracts where final price includes an additional, post-competition transfer. Thus, competition only pins down the reference point in rigid contracts. So buyers with flexible contracts are obliged to pay higher total transfers to induce a given quality level.

We chose to have competition play no role in our bilateral negotiation setting, so HM is not directly applicable. However, we believe that the basic intuition - that flexibility may suffer 
from disagreement costs - still applies. The reason is that clear bilateral agreements can readily influence subsequent perceived entitlements.

In particular, it is unreasonable for a seller to expect more than the base price after agreeing to a rigid contract; peers could tell the seller, "you chose to accept that price, so you cannot complain now!" ${ }^{19}$ Consider a seller who abides by the more general norm of living with the consequences of his actions. ${ }^{20} I f$ he accepts a rigid price, he will not later feel entitled to a transfer above that price. The buyer can therefore obtain at least normal quality by setting a rigid price sufficient to avoid rejection. By contrast, a flexible contract does not benefit from this norm unless it clearly defines what consequences the seller is accepting. ${ }^{21}$ Clarity on Q demands specifying $\mathrm{Q}$ for each cost state and this requires communication. We can therefore generalize HM's prediction that traders may prefer rigid over flexible contracting to noncompetitive settings with bilateral bargaining, provided that communication is restricted. As quality has substantial efficiency implications, we have:

\section{Conjecture A: In the no-chat treatment, rigid contracts will be more frequent than flexible contracts.}

This conjecture does not apply to contexts where communication allows traders to discuss, clarify and adjust their intentions and expectations over the additional transfer. We predict that traders with access to a free (bilateral) communication channel will find a way to negotiate a clear plan (leaving no room for disagreement) even when adapting transfers to the state. Traders have a strong incentive to avoid disagreement costs in this way and our chat

\footnotetext{
${ }^{19}$ There may be exceptions. The seller might claim to have only accepted in order to better punish the buyer for an aggressive proposal, but this is only reasonable when the buyer's price is so blatantly low as to merit punishment beyond rejection (and even then such heavier punishment is impossible for very low prices).

${ }^{20}$ This norm is captured in the commonplace refrain, "you've made your bed - now lie in it" (see e.g. Peterson, 2012). The Austrian School motivate the norm by arguing, in Hayek's (1960, pp.76-77) formulation, that society should encourage reasonable behavior by "letting [people] bear the consequences of their decisions". This norm applies for consequences of agreements that a reasonable person could anticipate at the time of agreement.

${ }^{21}$ Otherwise, the seller could claim to have only accepted in expectation of a high additional transfer.
} 
treatment makes such clear agreements possible: traders can specify Q in each state. Flexible contracting then has only advantages. It permits sharing of the seller's cost shock, which raises social surplus if the seller is risk averse or if either trader is inequality averse. As noted in 4.1.1, such sharing is credible, especially with communication, so we predict:

Conjecture B: In the chat treatment, flexible contracts will predominate.

\subsubsection{Other effects of communication.}

In addition to clarifying the size of $\mathrm{Q}$ transfers, communication raises social proximity. This enhances social comparison and group efficiency concerns and mutual consideration (chats tend to stay friendly in simple cooperative games like ours); see e.g., Sally (1995). Enhanced inequality and efficiency concerns raise the value of cost sharing. In addition, the ability to make promises and show mutual respect greatly enhances trust. The enhanced trust raises the credibility of cost sharing. Both effects increase the advantage of flexibility.

These effects support our Conjecture B above, but notice that the social-preference channel cannot explain why rigid contracts should be more frequent in the no-chat treatment, as in our conjecture A. The ambiguity and clarification story is therefore the most parsimonious explanation of the shift from rigid to flexible. Nonetheless, in our analysis of chats we look for evidence supporting these social preference effects as well as our clarification effect. Finally, the social-preference effects just noted all raise transfers and quality as shown in 4.1, so we predict:

Conjecture $C$ : Communication raises quality $x$, total transfers $T$ ( $P$ for rigid contracts and $P+Q$ for flexible ones) as well as (in flexible contracts) the degree of cost sharing, $d Q=$ $\mathrm{Q}(20)-\mathrm{Q}(0)$.

\subsection{Earnings levels}

We make essentially the same predictions for buyer and seller earnings as a function of 
contract type as we did for the frequency of contract type selection. As in HM, traders pick the contract type that works best for them, as reasonably captured by total material earnings (money is transferable). So we predict that total earnings will be higher for rigid contracts in the no-chat treatment and higher for flexible contracts in the chat treatment (experimentation and contract selection error offer simple ways to explain the presence of both contract types). We predict the same for buyer and seller earnings (though more tentatively for seller earnings in the no-chat treatment - see the caveat footnote below). In sum, we can restate the three conjectures above in terms of earnings: treatment. $^{22}$

Conjecture A': Buyer and seller earnings are higher for rigid contracts in the no-chat Conjecture B': Buyer and seller earnings are higher for flexible contracts in the chat treatment.

Conjecture C': Communication raises buyer and seller earnings.

\subsection{The effect of chat categories}

If clarification is the driving factor behind the shift to flexible in the chat treatment, we should observe a strong use of clarification in the chats that accompany flexible contracts. However, as discussed above, we also have to pay attention to the social-preference effects of communication. We therefore focus our conjectures on the effects of the clarification of Q and two other chat categories that capture the main social preference channels described in 4.1 and 4.2.1. More specifically, since there is no role for clarification in rigid contracts, we predict:

Conjecture D: Flexible contracts accompanied by clarification chats are more effective than

\footnotetext{
${ }^{22}$ There is a caveat: the seller earnings prediction is tentative, because sellers might possibly gain from flexible contracts if buyers anticipate how ambiguity can require higher transfers (no-chat case). This caveat is minimal for $\mathrm{B}^{\prime}$, because in the chat treatment, contract type preferences are more aligned: first, buyers can remove ambiguity; second, sellers can pressure buyers to share the pie similarly for each contract type (approximately equally in the data) and sellers can influence contract choice.
} 
when chats are not clarifying.

Conjecture E: Flexible and rigid contracts accompanied by friendly chats are more effective than when chats are not friendly.

Conjecture F: Flexible and rigid contracts accompanied by seller promises are more effective than chats not accompanied by seller promises.

\section{Experimental results}

In this section, we first provide descriptive statistics and then non-parametric tests on the outcomes observed in our two treatments. We focus on the overall effect of communication and on how the presence of communication affects the comparison between rigid and flexible contracts. We then discuss the patterns observed in the chat treatment and their correspondence to the ensuing behavior. We close section 5 with regression analysis of the various factors affecting the choices made.

\subsection{Descriptive statistics}

We present information about the contracts chosen, prices and transfers, quality levels and earnings in the no-chat and chat treatments in Tables 1 and 2, respectively. We first describe the results and later provide statistical tests.

In Table 1, we see that rigid contracts are chosen 11 percentage points more frequently in the no-chat treatment. Most sellers choose normal quality given either contract type, with the bulk of the rest sacrificing money to hurt the buyer; the rate of inferior quality is slightly higher with flexible contracts. Average quality is somewhat higher for rigid than flexible contracts, both with and without a cost shock. Buyer and seller earnings are higher for rigid contracts, with and without a cost shock. The contract rejection rate is just under one-third for both forms of contract. Total transfers $(\mathrm{P}+\mathrm{Q})$ are slightly higher for flexible contracts when there is a cost 
shock, while this is reversed when there is no cost shock. The bottom line is that rigid contracts are used more frequently and are somewhat better for both sides of the market, when communication is not feasible.

[Tables 1 and 2 about here]

Comparing Tables 1 and 2, one can see the impact of communication. For both types of contract, the rejection rate with communication is greatly reduced from the rejection rate without communication, particularly with flexible contracts (down from 33.2 percent to 3.7 percent!). In the chat treatment, the flexible contract becomes the more frequent choice: the proportion of flexible contracts chosen increases from 44.6 percent in the no-chat treatment to 74.7 percent in the chat treatment.

With a cost shock, the total price paid ${ }^{23}$ is now higher for flexible contracts than for rigid ones. In contrast, total prices are very similar without a cost shock. In addition, the price is now more sensitive to the cost shock: under flexible contracts, the price is 5.83 units higher after the (20-unit) cost shock than after no shock; this represents 58.3 percent of full cost sharing. In contrast, in the absence of communication, the increase of the total price in a flexible contract with the cost shock is only 1.77 units (17.7 percent of full cost sharing). This suggests that communication facilitates the use of higher $\mathrm{Q}$ in response to a cost shock and may well serve to limit its negative effect on quality.

Quality is now much higher than without communication for both contract types (with and without the cost shock). In addition, while in the absence of communication quality was higher with rigid contracts, it is now higher with flexible contracts. The likelihood of inferior

\footnotetext{
${ }^{23}$ In this section and regressions, we refer to the total transfer, $\mathrm{T}=\mathrm{P}+\mathrm{Q}$, as total price paid, simplifying to price paid or price, but always writing out "initial price" to identify P and "additional transfer" to indicate Q.
} 
quality is reduced from 31.1 percent to 14.3 percent with rigid contracts and from 40.5 percent to 6.3 percent with flexible contracts; we see corresponding (and even more dramatic) increases in the likelihood of superior quality, from 3.7 percent to 49.4 percent with rigid contracts and from 3.0 percent to 74.3 percent with flexible contracts.

The next question is how the presence of communication affects earnings. Starting with rigid contracts one can see that buyer earnings are slightly higher without a cost shock (15.28 to 16.98), but slightly lower (12.27 to 11.87 ) with a cost shock. Averaged over the cost shock, buyer earnings increase from 10.80 to 12.66 . Seller earnings with rigid contracts increase substantially both with and without a cost shock.

In contrast to the case for rigid contracts, for flexible contracts, both buyer and seller earnings' increase substantially whether or not a cost shock occurs. In fact, total earnings increase by 128 percent across treatments with flexible contracts, compared to an increase of 58 percent with rigid contracts.

Overall, it is clear that communication leads to a much higher proportion of flexible contracts, higher prices, higher quality, fewer rejections, and greater earnings for both sides. We end the section by looking at behavior over time. Figures 1,2 and 3 show the trends over time in each treatment for the proportion of proposed contracts that are flexible, average quality levels and average earnings, respectively. In the chat treatment, the increase in the proportion of flexible contracts is substantial, from $60 \%$ in the first two periods to $80 \%$ in the final two periods, suggesting that traders learn to use flexible contracts more as their experience increases; a simple random-effects regressions (clustered by individual; available on request) confirms that there is a strong increasing trend towards flexible contracts. In the no-chat treatment, there is initially a modest positive trend but it flattens off by periods 5-6. With respect to both quality and 
total earnings, we find a pattern of significant (positive) change over time in the chat treatment but no significant trend without communication; quality increases from 0.50 in the first two periods to 0.69 in the final two periods while total earnings increases from 30.7 to 38.2.

[Figures $1-3$ about here]

\subsection{Non-parametric tests}

In this section we present the results of statistical tests of the conjectures developed in section 4. We perform non-parametric tests of the differences we have just highlighted on two levels. A conservative testing philosophy treats each session as exactly one observation, so that we only have four observations from each treatment; the data for each session is presented in Appendix B. A more powerful but less pure statistical approach is to consider the aggregate behavior and outcomes for each individual. The individual-level tests that we present below are based on seller-level data, that is, for each seller, we average the values of the relevant variable over that seller's ten active matches with buyers. ${ }^{24}$

We start with rejection rates (not explicitly covered by our conjectures). The average rejection rate (over all contract offers) is far higher without communication, 32.8 percent versus 7.3 percent. This also holds when breaking down by contract type, especially for flexible contract offers: for rigid contract offers, the difference is significant at the individual level, but not at the session level (the Wilcoxon-Mann-Whitney ranksum test gives $Z=1.88, p=0.030$,

\footnotetext{
${ }^{24} \mathrm{We}$ cannot control for both buyer and seller fixed effects at the same time, since we have no repeated interactions. We expect buyer fixed effects to be less important (even self-interested buyers will share 50:50 if this is needed to get a high quality response, meanwhile sellers move last and variations in their sense of entitlement have large payoff implications for buyers). In fact, variation among sellers seems to have more impact than buyer variation. The relative standard error (RSE) of quality $x$ (chosen by sellers) is greater than the RSE of total transfer (chosen by buyers) in accepted contracts: for quality, the RSE's are 0.1305 (overall), 0.0977 (no-chat), and 0.0520 (chat); as for total transfers, the RSE's are $0.0180,0.0445$, and 0.0113 , respectively. So we control for seller fixed effects by using seller-level data in the signed-rank tests. Buyer-level data gives similar results but somewhat less significance.
} 
and $p=0.343$, respectively, one-tailed tests); ${ }^{25}$ for flexible contracts, the difference in rejection rates is stronger and significant; we have $Z=5.34, p=0.000$, and $p=0.014$, one-tailed tests, for the individual- and session-level ranksum tests. ${ }^{26}$ The main effect is consistent with the idea that communication allows traders to coordinate (agree) on mutually acceptable terms of trade. ${ }^{27}$

Next we present results on tests of the conjectures about contract frequencies. Conjecture A posits that in the no-chat treatment, rigid contracts will be more frequent than flexible contracts, while conjecture B proposes that in the chat treatment flexible contracts will predominate. A Wilcoxon signed-ranks test shows that there is a marginally significant difference at the individual level in the proportions of rigid and flexible contracts in the no-chat treatment $(Z=1.53, p=0.063$, one-tailed testing, in keeping with the FHZ results; at the session level, there are two sessions with more rigid contracts and two sessions with flexible contracts). Despite the support (below) for the earnings predictions that motivate conjecture A, the (revealed preference) support for conjecture A itself is fairly weak (relatedly, in FHZa, the two contract types are chosen exactly equally); this is not surprising given that the earnings differences are small in magnitude and we do not provide average earnings feedback. On the other hand, we find clear differences at both the individual and session levels in the chat treatment (one-tailed signed-ranks tests give $Z=5.51, p=0.000$, for individual data and $p=0.063$ at the session level since there were more flexible contracts than rigid contracts in each of the four chat sessions). Hence, our result are consistent with conjectures A and B, although weakly so in the case of conjecture A.

\footnotetext{
${ }^{25} \mathrm{We}$ round all $p$-values to the third decimal place.

${ }^{26}$ In the 18 instances of the chat treatment where there is no actual conversation, there are nine rejections (six with rigid contracts and three with flexible contracts), and only one case where the quality level is superior. So when there is a conversation there are only 23 rejections, implying a rejection rate of 5.3 percent (13.9 percent with rigid contracts and 2.8 percent with flexible contracts).

${ }^{27}$ Also, we expect sellers to reject rigid contracts more than flexible ones (indeed five times as often) in the chat treatment, because seller profits are higher with flexible (as predicted by conjecture $\mathrm{B}^{\prime}$ ).
} 
Conjecture $\mathrm{C}$ proposes that communication will lead to an increase in quality $x$, total transfers $\mathrm{T}$, and (for flexible contracts) the degree of cost sharing dQ. We start with the tests of the quality differences. Tests of quality across treatments, measured on the individual and session levels (using averages), give $Z=7.48, p=0.000$ and $p=0.014$, respectively, one-tailed ranksum tests. ${ }^{28}$ There is a higher rate of seller cooperation (superior quality) in each of the four chat sessions than in any of the four no-chat sessions, and the reverse is true for inferior quality. Remarkably, only two of 44 sellers provided positive average quality in the no-chat treatment, while all 44 sellers did so in the chat treatment.

Furthermore, quality is higher with rigid contracts than with flexible contracts in each session of the no-chat treatment, while the order is reversed in each session of the chat treatment ( $p=0.063$ in both cases for one-tailed signed-ranks session-level tests). Comparing within individuals, we find that quality is significantly lower for flexible contracts than for rigid contracts in the no-chat treatment, $Z=2.10, p=0.018$, while quality is significantly higher for flexible contracts than for rigid contracts and $Z=3.61, p=0.000$ in the chat treatment. Regarding superior quality, there is no significant difference in the no-chat treatment $(Z=0.21)$, but a very significant one in the chat treatment $(\mathrm{Z}=2.78, p=0.003$, one-tailed test), with flexible contracts leading to considerably more high quality choices.

We find that (total) prices paid in the chat treatment are typically considerably higher than in the no-chat treatment. The total price in rigid contracts (here equal to initial price $\mathrm{P}$ ), the initial price $\mathrm{P}$ in flexible contracts, and the discretionary additional transfer $\mathrm{Q}$ in flexible contracts are all significantly higher in the chat treatment at $p=0.000$ on the individual level and $p=0.057$ on the session level (one-tailed tests). Total prices paid for accepted rigid and flexible

\footnotetext{
${ }^{28} \mathrm{We}$ exclude rejected contract offers in tests on quality and transfers (below), because there we do not observe quality choices and additional transfers (flexible case).
} 
contracts are similar, with no significant differences in either treatment. The difference in the values of $\mathrm{Q}$ is significant in the chat treatment $(Z=4.70, p=0.000$, signed-ranks test with individual-level data) but not in the no-chat treatment $(Z=0.766, p=0.444)$. This supports the prediction that buyers are more likely to compensate sellers for adverse cost shocks when communication is feasible. The results presented in these last four paragraphs are consistent with all three parts of conjecture C.

We next turn to the conjecture about earnings. Are earnings higher when buyers propose rigid or flexible contracts? According to conjecture A', buyer and seller earnings should be higher for rigid contracts in the no-chat treatment. We find that earnings are slightly higher for both buyers and sellers. One-tailed Wilcoxon signed-ranks tests on seller-level data show that the differences are significant for buyers $(p=0.030)$ and marginally significant for sellers $(p=$ 0.061). Given the caveat on the seller prediction (footnote 22), these test results are acceptably consistent with conjecture $\mathrm{A}^{\prime}$. When communication is feasible, the flexible contract is notably more profitable for both buyers and sellers, consistent with our conjecture B'. Wilcoxon signedranks tests show statistically-significant differences for buyer, seller, and total earnings, using individual-level data (the $Z$-statistics are 2.77 for buyers, 2.93 for sellers, and 3.40 for the total earnings, all significant at $p<0.003$, one-tailed tests).

We close the section with the test results that show that observed behavior is consistent with conjecture $\mathrm{C}^{\prime}$, which proposes that communication will raise both buyer and seller earnings. Nearly all sellers in the chat treatment had higher earnings than sellers in the no-chat treatment. The Wilcoxon rank-sum test gives $Z=8.05, p=0.000$ on the individual level and $p=0.014$ on the session level (in every chat session, the earnings are higher than in any no-chat session). While the divergence in buyer earnings across treatments is not quite as extreme, the rank-sum 
test still finds a clear significant difference using both individual-level data $(Z=5.89, p=0.000)$ and session-level data $(p=0.014)$. Total earnings are higher in each session of the chat treatment, than in any session of the no-chat treatment, giving $p=0.014$, one-tailed test.

\subsection{Regression analysis of earnings levels}

In this section, we analyze the determinants of earnings using regression analysis. The results essentially corroborate those obtained with non-parametric tests reported above and allow us to study the impact of prices on earnings levels. We will be able to highlight some differences in the process of earnings determination of buyers and sellers.

The regressions are shown in Table 3. Our simplest specifications, (1) and (4), include only "Period", "Treatment" and "Cost shock" as independent variables. The results for these specifications show that both buyers and sellers earn significantly more in the chat treatment, as seen by the significant coefficient for the "Treatment" dummy. Being in the chat treatment by itself implies higher earnings for both buyers and sellers, with the effect being much stronger for sellers. Naturally enough, a cost shock affects earnings negatively for the seller (who bears the direct cost), but also for the buyer (who shares the burden to some extent). In addition, there is some increase over time in seller earnings but not in buyer earnings, as Figure 3 suggests.

In specifications (2) and (5) we add "Flexible" and an interaction variable "Treatment*flexible". Including those variables allows us to confirm and qualify some of the results revealed by the non-parametric tests discussed in the previous section. Using a flexible contract has by itself no effect on earnings of either buyers or sellers. It is the interaction variable "Treatment*flexible" that has a strong positive effect on the earnings of buyers and sellers. This is consistent with our non-parametric results and adds support for our predictions that 
communication has a positive level effect on earnings and that communication complements flexible contracting.

Specifications (3) and (6) provide insight into how prices affect earnings levels. Recall from footnote 23, that "Price paid" refers to the total transfer or sum of initial price P and additional transfer $\mathrm{Q}(\mathrm{T}=\mathrm{P}+\mathrm{Q}$; simply equal to $\mathrm{P}$ in the case of rigid contracts). As seen in the $\mathrm{R}^{2}$ for specification (3) and (6), including the price paid, its square, and price-interaction terms greatly adds to the explanatory power of the regressions. ${ }^{29}$ Both buyer and seller earnings increase with the price paid, tempered slightly by the negative coefficient on the price-squared term. Higher prices directly favor sellers. What is more remarkable is that buyers also profit from higher prices, presumably because they are associated with higher quality levels, which have a strong impact on buyer earnings. The negative coefficient on price squared (for buyers) reflects the decreasing returns to, and upper bound on, quality; for sellers, the effect is far smaller and reflects how seller cost initially decreases and then increases as price increases first shift $x$ from 1 to 0 and then to +1 . The impact of price on buyer and seller earnings does not differ statistically between contract types, as evidenced by the lack of significance of the "Price paid*flexible" variable in specifications (3) and (6).

There are some differences in the earnings determination of buyers and sellers. First, the inclusion of the price variables does not alter the insignificant effect of time on buyer earnings, but changes the impact on seller earnings from a significantly positive effect to a significantly negative albeit smaller effect (consistent with buyers learning to raise prices). Second, with price variables included, the effect of "Treatment" continues to be significantly positive (but much smaller) for seller earnings, but no longer significant for buyer earnings. At the same time, the

\footnotetext{
${ }^{29}$ The explanatory power of the final regressions (controlling for price paid and cost shock) is unusually high, reflecting the fact that the seller's payoff is almost fully determined by price paid and cost shock. This is because quality choice $x$ barely affects cost. Nonetheless, quality has a big impact on the buyer (and so on contract design).
} 
coefficient on "Treatment*flexible" remains strongly positive in the buyer earnings specification (3), but is now not significant in the seller earnings specification (6). We interpret this to mean that the possibility of communicating with sellers allows buyers to use flexible contracts to obtain higher quality increases, controlling for prices. In contrast, for sellers, it is purely the possibility of communicating and not particularly the fact of communicating in the context of flexible contracts that has a positive effect on earnings.

[Table 3 about here]

Third, specification (3) shows that the negative effect of the cost shock on buyer earnings is captured through the terms involving the price paid. This is natural: cost shocks induce buyers to raise prices paid to share in seller cost burdens but have no direct effect on buyers. By contrast, specification (6) shows that these higher prices only partially mitigate the negative effect of cost shocks on seller earnings.

\section{Discussion and analysis of chat data}

We have seen that communication leads to a far higher proportion of flexible contracts, and is very effective in achieving higher prices, quality, and earnings. But which elements of the contents of this communication drive this result? And how well do the patterns that we observe fit with our theoretical predictions? We discuss these issues in turn.

\subsection{Message content}

We developed and implemented a systematic scheme for coding message content. Our methods paralleled those employed by Cooper and Kagel (2004), Brandts and Cooper (2007) and Ellman and Pezanis-Christou (2010). The coding of our chats was a demanding task, since a buyer and seller could communicate starting from the time they were matched together until the 
moment the seller made the quality decision.

We began by positing some coding categories based on our theoretical framework presented in section 3 and prior research. Having read a sample of chats, we then developed a provisional coding scheme, which included categories based on our theoretical approach and others that appeared to be relevant based on our reading of the chat samples. Two research assistants (RAs) then independently coded the chats between all matched buyers and sellers. We then looked at the results of the coding and refined the coding scheme to improve on some of the ambiguities of the first coding scheme. Finally, we gave the new coding scheme to a new research assistant who then independently coded all chats again.

At no point in the process of developing or implementing the coding scheme were any of the RAs informed about any hypotheses the co-authors had about the messages. The RAs were repeatedly and explicitly told that their job was to capture what had been said rather than why it was said or what effect it had. Coding was primarily binary - with a small number of exceptions, a message was coded as a 1 if it was deemed to contain the relevant category of content and zero otherwise. We had no requirement on the number of codings for a message - the coder could check as many or few categories as he or she deemed appropriate.

The eighteen coding categories that we used are shown in Appendix D. Tables C1, C2, and $\mathrm{C} 3$ in Appendix $\mathrm{C}$ show the average values for each category both overall and for the nochat and chat treatments separately. We briefly discuss some of the coding values for each category. The frequency of use varies widely: for instance, only $1.7 \%$ of conversations mention problems of cost risk as a reason for choosing the rigid contract while in $73.4 \%$ of the conversations, the buyer pressures the seller to set a reasonable quality ( $x=1$ or 0$)$. Comparing the coding values between matches in which a rigid contract emerged and those in which a 
flexible contract emerged, the entries in tables $\mathrm{C} 2$ and $\mathrm{C} 3$ show clearly that the coding values tend to be higher for flexible contracts than for rigid ones. That is, conversations had more overall content in cases with a flexible contract.

More importantly, the key chat categories are used more frequently in connection to flexible contracts. The frequency of $Q$-clarification is 0.109 with rigid contracts and a remarkable 0.866 with flexible contracts. Promises by the seller about the quality he/she will set have a frequency of 0.307 with rigid contracts and of 0.488 with flexible ones. ${ }^{30}$ For Friendly the frequencies are 0.119 vs. 0.419 respectively. There is a high degree of correlation between various categories, as seen in Table $\mathrm{C} 4$ of Appendix C. For instance, Q-clarification and Friendly are significantly correlated with most other categories.

\subsection{Support for theoretical conjectures about chat content}

Conjectures D, E, and F predict how three different chat categories affect earnings. Average total earnings for flexible contracts with and without Q-Clarification were $39.07(0.89)$ and 33.84 (2.33), respectively (standard errors in parentheses). A regression (clustered by individual sellers and controlling for total price and cost shock) with total earnings as the dependent variable finds that the coefficient for $Q$-Clarification is highly significant $(Z=3.18, p$ $=0.002$, one-tailed test) for flexible contracts. Meanwhile for rigid contracts, average total earnings with and with clarification were 29.55 (5.72) and 30.46 (1.94), respectively. A similar regression finds that the coefficient for $Q$-Clarification is not significant $(Z=1.12, p=0.263$, two-tailed test for our non-directional hypothesis here) for rigid contracts. This evidence is consistent with both parts of Conjecture D.

\footnotetext{
${ }^{30}$ Promise-keeping was as follows: There were 185 cases in which a promise was made concerning $x$ and a contract was accepted; high quality was delivered 146 times ( 78.9 percent), regular quality 29 times (15.7 percent), and low quality 10 times (5.4 percent).
} 
The data are also consistent with conjecture E. Average total earnings for flexible contracts with and without Friendly were 43.08 (0.92) and 36.03 (1.23); the same type of regression as in the previous paragraph finds that the coefficient on Friendly is highly significant $(Z=5.95, p=0.000$, one-tailed test). Average total earnings for rigid contracts with and without Friendly were 41.27 (2.87) and 29.57 (2.23); a similar regression finds that the coefficient on Friendly is significant $(Z=2.18, p=0.015$, one-tailed test). Thus, there is strong support for Conjecture $\mathrm{E}$ for both flexible and rigid contracts.

Finally, average total earnings for flexible contracts with and without seller promises were 38.87 (1.10) and 36.03 (1.23); the above type of regression finds that the coefficient on Promises over $x$ is quite significant $(Z=3.12, p=0.004$, one-tailed test). Average total earnings for rigid contracts with and without seller promises were 37.74 (3.14) and 27.09 (2.14); a similar regression finds that the coefficient on Promises over $x$ is marginally significant $(Z=1.29, p=$ 0.099, one-tailed test). Thus, Conjecture F receives moderate support.

We also check for differences using non-parametric tests, though these tests do not control for other variables. Using Wilcoxon signed-rank tests on the individual seller level, we find supportive evidence for $\mathrm{D}(Z=1.32, p=0.093$, one-tailed test, for flexible contracts and $Z=$ $-0.280, p=0.779$, two-tailed test, for rigid contracts), significant evidence for $\mathrm{E}(Z=3.27, p=$ 0.001 for flexible contracts and $Z=2.58, p=0.005$ for rigid contracts, one-tailed tests), but no support for $\mathrm{F}(Z=0.53, p=0.298$ for flexible contracts and $Z=-0.64, p=0.761$ for rigid contracts, one-tailed tests).

In sum, there is evidence that Q-clarification helps in flexible and not in rigid, while Friendly and (to a lesser extent) Promises over $x$ help in both types of contract, as predicted in Conjectures D, E and F. 


\section{Conclusion}

In principle, flexible contracts are superior to rigid ones, because traders can then adapt their terms of trade to better reflect the changing state of the world. Yet ambiguity over how to interpret flexible contracts may make it useful for traders to tie their hands. A flexible contract can leave considerable room for disagreement after an event such as a cost shock and disagreements can result in dissatisfaction with a concomitant risk of low quality. Recent work has found that in fact there are laboratory environments where rigid contracts are better than flexible ones (at least for buyers).

Our results without communication qualitatively confirm and generalize these ideas. We find it interesting that the advantage of rigid contracts in the absence of communication is robust to a number of design features. The fundamental intuition - that flexible contracts leave room for disagreements where sellers feel mistreated and supply inefficiently low quality appears quite solid. Indeed, our no-communication results provide support for the so far unconfirmed prediction of HM that flexibility can lead to reduced social welfare: we find that not only buyers but also sellers earn less with flexible contracts than with rigid ones. Furthermore, we find that rigid contracts are more frequent than flexible contracts in this case.

But is the problem flexibility per se, or is it the ambiguity of the situation that drives this result? Not much can be done to achieve better efficiency if the former is the case. However, there are ways in which one can ameliorate ambiguity and potentially induce better social outcomes in the latter case. In this paper, our most important contribution is to test for the effect of unrestricted communication on the nature and effectiveness of contracting. We see that matters change dramatically when the contracting parties are able to freely communicate from 
before trade is agreed until the seller chooses quality. With this natural feature, people can make agreements (that remove the ambiguity in flexible contracts) and promises (which, though unenforceable, tend to be honored); this leads to higher transfers and higher quality.

Our results show that transfers are higher, quality is higher, and earnings are substantially greater for both sides when unrestricted communication becomes feasible. Flexible contracts then emerge as the instrument that allows traders to raise efficiency. They become increasingly frequent over time, consistent with the view that traders experiment and learn across rounds that flexible works best.

We also propose a conceptual approach that formalizes the intuition that free communication helps to align expectations and resolve ambiguity. In line with this, content analysis of our chat data reveals that clarification of the transfer plan is associated with better quality and earnings outcomes in flexible contracts. ${ }^{31}$ In general, we find that it is not flexibility per se that causes problems in the contractual environment, but rather the risk of ambiguity over how flexible contract terms are to be adapted to subsequent events. Free (but still anonymous) communication appears to largely resolve this ambiguity while preserving the adaptive benefits of flexibility. Overall, our work points to large benefits from informal agreements when traders cannot write complete state-contingent (formal) contracts.

In light of these sharp implications for contract design, it is important to know whether the presence or absence of communication channels between buyers and sellers is the more relevant case. Instances in which communication is simply not feasible (or is very limited) do exist, but are rare because of the large overall inefficiencies with restricted communication.

\footnotetext{
${ }^{31}$ For the decision-responsibility norm to apply, this clarification must occur ex ante; while we allow communication throughout, the results of our chat content analysis offer some support for the prediction that it is the ex ante communication captured by the Q-clarification category that enables flexible contracts to work well. In addition, find that communication improves outcomes for both types of contract when chats indicate mutual respect and contain promises.
} 
Moreover, our results clearly support the intuition that traders have very strong incentives for finding ways to communicate (exchanging views and clarifying plans). Of course, communication is much more difficult in more complex environments where traders with different experiences may fail to understand each other's perspectives and explain their own plans without ambiguity. Such environments are extremely difficult to analyze in a controlled fashion.

Nonetheless, we do wish to point out a potential limitation of our study (and the other studies) that is more amenable to investigation. We consider symmetric information, in that both parties observe the cost shock. Yet even small information asymmetries could potentially lead to substantial distortion, limiting the power of communication. Results from Charness and Dufwenberg $(2006,2011)$ indicate that free-form communication can strongly facilitate efficient outcomes even in asymmetric information environments with moral hazard and adverse selection, but the impact might be different here. We believe this issue calls for future research. 


\section{References}

Andreoni, James (1990), "Impure Altruism and Donations to Public Goods: A Theory of Warm-Glow Giving?,” Economic Journal, 100, 464-77.

Andreoni, James (2005), "Trust, Reciprocity, and Contract Enforcement: Experiments on Satisfaction Guaranteed," mimeo.

Aumann, Robert (1990), "Nash-Equilibria are not Self-Enforcing," in Economic Decision Making: Games, Econometrics and Optimisation (J. Gabszewicz, J.-F. Richard, and L. Wolsey, Eds.), 201-206. Amsterdam: North-Holland.

Ben-Ner, Avner, Louis Putterman and Ting Ren (2011), "Lavish Returns on Cheap Talk: Non-binding Communication in a Trust Experiment," Journal of Socio-Economics, 40, 1-13.

Bolton, Gary and Axel Ockenfels (2000), "ERC: A Theory of Equity, Reciprocity, and Competition," American Economic Review, 90, 166-193.

Brandts, Jordi and David Cooper (2007), "It's What You Say Not What You Pay: An Experimental Study of Manager-Employee Relationships in Overcoming Coordination Failure," Journal of the European Economic Association, 5, 1223-1268.

Charness, Gary (2000), "Self-serving Cheap Talk and Credibility: A Test of Aumann's Conjecture," Games and Economic Behavior, 33, 177-194

Charness, Gary and Martin Dufwenberg (2006), "Promises and Partnership," Econometrica, 74, 1579-1601.

Charness, Gary and Martin Dufwenberg (2010), "Bare Promises: An Experiment," Economics Letters, 107, 281283.

Charness, Gary and Martin Dufwenberg (2011), "Participation," American Economic Review, 101, 1211-1237.

Charness, Gary and Matthew Rabin (2002), "Understanding Social Preferences with Simple Tests," Quarterly Journal of Economics, 117, 817-869.

Cooper, Russell W., Douglas V. Dejong, Robert Forsythe and Thomas Ross (1990), "Selection Criteria in Coordination Games: Experimental Results," American Economic Review, 80, 218-233.

Cooper, David and John Kagel (2004), "Are Two Heads Better than One? Team vs. Individual Play in Signaling Games," American Economic Review, 95, 477-509.

Ellingsen, Tore and Robert Östling (1989), "When Does Communication Improve Coordination?," American Economic Review, 100, 1695-1724.

Ellman, Matthew and Paul Pezanis-Christou (2011), "Organizational Structure, Communication and Group Ethics," American Economic Review, 100, 2478-2491.

Erlei, Matthias and Christian Reinhold (2011), "To Choose or Not to Choose: Contracts, Reference Points, Reciprocity, and Signaling," working paper.

Fehr, Ernst, Oliver Hart and Christian Zehnder (2009), "Contracts, Reference Points, and Competition - Behavioral Effects of the Fundamental Transformation," Journal of the European Economic Association, 7, 561-572.

Fehr, Ernst, Oliver Hart and Christian Zehnder (2011A), "Contracts as Reference Points - Experimental Evidence," American Economic Review, 101, 493-525.

Fehr, Ernst, Oliver Hart and Christian Zehnder (2011B), "How Do Informal Agreements and Renegotiation Shape Contractual Reference Points?," working paper.

Fehr, Ernst and Klaus Schmidt (1999), “A Theory of Fairness, Competition, and Cooperation,” Quarterly Journal of Economics, 114, 817-868.

Hart, Oliver (1995), Firms, Contracts, and Financial Structure, Clarendon Press, Oxford.

Hart, Oliver and John Moore (2008), "Contracts as Reference Points," Quarterly Journal of Economics, 123, 1-48.

Hayek, Friedrich (1960), The Constitution of Liberty, University of Chicago Press.

MacLeod, W. Bentley (2007), "Reputations, Relationships, and Contract Enforcement," Journal of Economic Literature, 45, 595-628.

Maskin, Eric and Jean Tirole (1999), "Implementation and Renegotiation," Review of Economic Studies, 66, 39-56.

Oprea, Ryan, Gary Charness and Daniel Friedman (2012), "Continuous Time and Communication in a Public-goods Experiment," mimeo.

Peterson, Eugene (2012), Proverbs 1:29, The Message (www.biblegateway.com).

Sally, David (1995) "Conversation and Cooperation in Social Dilemmas: A Meta-Analysis of Experiments from 1958 to 1992," Rationality and Society, 7, 58-92.

Sobel, Joel (2005), “Interdependent Preferences and Reciprocity,” Journal of Economic Literature, 93, 392-436. 
Table 1: Behavior in the no-chat treatment

\begin{tabular}{|c|c|c|}
\hline Category & Rigid contract & Flexible contract \\
\hline Frequency* & $243(55.4 \%)^{\wedge}$ & $196(44.6 \%)^{\wedge}$ \\
\hline Rejections & $79(32.5 \%)$ & $65(33.2 \%)^{\wedge}$ \\
\hline Average P (all offers) & $13.28[0.41]$ & $11.13[0.37]^{\wedge}$ \\
\hline Average P (accepted offers) & $15.74[0.43]$ & $12.58[0.46]^{\wedge}$ \\
\hline Average Q with cost shock & - & $3.35[0.49]$ \\
\hline Average Q with no cost shock & - & $1.58[0.30]^{\wedge}$ \\
\hline Inferior quality & $51(31.1 \%)$ & $53(40.5 \%)^{\wedge}$ \\
\hline Normal quality & $107(62.2 \%)$ & $74(56.5 \%)^{\wedge}$ \\
\hline Superior quality & $6(3.7 \%)$ & $4(3.0 \%)^{\wedge}$ \\
\hline Avg. quality with cost shock & $-0.32[0.06]$ & $-0.45[0.06]$ \\
\hline Avg. quality if no cost shock & $-0.22[0.06]$ & $-0.26[0.08]^{\wedge}$ \\
\hline Avg. buyer earnings, cost shock & $12.27[0.58]$ & $10.16[1.17]$ \\
\hline Avg. buyer earnings, no cost shock & $15.28[1.06]$ & $14.91[1.26]^{\wedge}$ \\
\hline Avg. buyer earnings (overall) & $10.80[0.58]$ & $8.84[1.09]^{\wedge}$ \\
\hline Avg. seller earnings, cost shock & $0.80[0.61]$ & $0.27[0.82]$ \\
\hline Avg. seller earnings, no cost shock & $19.86[0.62]$ & $19.15[0.85]^{\wedge}$ \\
\hline Avg. seller earnings (overall) & $7.81[0.59]$ & $7.96[1.22]^{\wedge}$ \\
\hline Avg. total earnings, cost shock & $13.08[1.14]$ & $10.36[1.23]$ \\
\hline Avg. total earnings, no cost shock & $35.14[1.14]$ & $34.17[1.48]^{\wedge}$ \\
\hline Avg. total earnings (overall) & $18.61[0.88]$ & $16.80[0.99]^{\wedge}$ \\
\hline
\end{tabular}

* No contract was offered on one occasion. ${ }^{\wedge}$ We exclude one case in which the buyer received a very large negative payoff (in the final period). Average buyer, seller, and total earnings with cost shock or no cost shock refer to accepted contracts. Average.buyer, seller, and total earnings (overall) refer to all offered contracts. Except for row 3 (Average P (all offers)), all other values refer to accepted offers. Standard errors are in brackets. 
Table 2: Behavior in the chat treatment

\begin{tabular}{|c|c|c|}
\hline Category & Rigid contract & Flexible contract \\
\hline Frequency* & $111(25.3 \%)$ & $327(74.7 \%)$ \\
\hline Rejections & $20(18.0 \%)$ & $12(3.7 \%)$ \\
\hline Average P (all offers) & $22.76[0.83]$ & $16.91[0.37]$ \\
\hline Average P (accepted offers) & $25.22[0.72]$ & $17.22[0.47]$ \\
\hline Average Q with cost shock & - & $13.08[0.66]$ \\
\hline Average Q with no cost shock & - & $7.25[0.66]$ \\
\hline Inferior quality & $13(14.3 \%)$ & $20(6.3 \%)$ \\
\hline Normal quality & $33(36.3 \%)$ & $61(19.4 \%)$ \\
\hline Superior quality & $45(49.4 \%)$ & $234(74.3 \%)$ \\
\hline Avg. quality with cost shock & $0.19[0.10]$ & $0.63[0.05]$ \\
\hline Avg. quality if no cost shock & $0.52[0.11]$ & $0.73[0.04]$ \\
\hline Avg. buyer earnings, cost shock & $11.87[1.75]$ & $13.23[0.66]$ \\
\hline Avg. buyer earnings, no cost shock & $16.98[1.34]$ & $21.76[0.78]$ \\
\hline Avg. buyer earnings (overall) & $12.66[0.99]$ & $17.02[0.56]$ \\
\hline Avg. seller earnings, cost shock & $9.61[1.08]$ & $15.15[0.42]$ \\
\hline Avg. seller earnings, no cost shock & $29.55[0.93]$ & $28.01[0.29]$ \\
\hline Avg. seller earnings (overall) & $16.68[1.16]$ & $20.95[0.46]$ \\
\hline Avg. total earnings, cost shock & $21.49[1.77]$ & $28.37[0.79]$ \\
\hline Avg. total earnings, no cost shock & $46.52[1.75]$ & $49.76[0.73]$ \\
\hline Avg. total earnings (overall) & $29.34[1.72]$ & $37.97[0.84]$ \\
\hline
\end{tabular}

* No contract was offered on two occasions. Average buyer, seller, and total earnings with cost shock or no cost shock refer to accepted contracts. Average buyer, seller, and total earnings (overall) refer to all offered contracts. Except for row 3 (Average P (all offers)), all other values refer to accepted offers. Standard errors are in brackets. 
Table 3 - Determinants of earnings, Random-effects GLS regressions

\begin{tabular}{|c|c|c|c|c|c|c|}
\hline $\begin{array}{l}\text { Independent } \\
\text { variables }\end{array}$ & $\begin{array}{c}(1) \\
\text { Buyer }\end{array}$ & $\begin{array}{c}(2) \\
\text { Buyer }\end{array}$ & $\begin{array}{c}(3) \\
\text { Buyer }\end{array}$ & $\begin{array}{c}(4) \\
\text { Seller }\end{array}$ & $\begin{array}{l}(5) \\
\text { Seller }\end{array}$ & $\begin{array}{c}(6) \\
\text { Seller }\end{array}$ \\
\hline Period & $\begin{array}{c}0.086 \\
(0.112)\end{array}$ & $\begin{array}{c}0.027 \\
(0.113)\end{array}$ & $\begin{array}{l}-0.047 \\
(0.104)\end{array}$ & $\begin{array}{c}0.280^{* * * *} \\
(0.094)\end{array}$ & $\begin{array}{c}0.219 * * \\
(0.093)\end{array}$ & $\begin{array}{c}-0.012^{* *} \\
(0.068)\end{array}$ \\
\hline Treatment & $\begin{array}{c}5.735^{* * *} \\
(0.742)\end{array}$ & $\begin{array}{l}1.857^{*} \\
(1.091)\end{array}$ & $\begin{array}{c}1.309 \\
(1.144)\end{array}$ & $\begin{array}{c}13.276^{* * * *} \\
(0.572)\end{array}$ & $\begin{array}{c}9.206^{* * * *} \\
(0.899)\end{array}$ & $\begin{array}{c}0.170 * * * \\
(0.057)\end{array}$ \\
\hline Cost shock & $\begin{array}{c}-0.110^{* * *} \\
(0.033)\end{array}$ & $\begin{array}{c}-0.108 * * * \\
(0.033)\end{array}$ & $\begin{array}{l}0.150^{*} \\
(0.090)\end{array}$ & $\begin{array}{c}-0.559 * * * \\
(0.026)\end{array}$ & $\begin{array}{c}-0.566^{* * *} \\
(0.026)\end{array}$ & $\begin{array}{c}-1.029 * * * \\
(0.004)\end{array}$ \\
\hline Flexible & - & $\begin{array}{l}-1.017 \\
(0.919)\end{array}$ & $\begin{array}{l}-0.887 \\
(1.102)\end{array}$ & - & $\begin{array}{l}-0.827 \\
(0.726)\end{array}$ & $\begin{array}{c}-0.065 \\
(0.050)\end{array}$ \\
\hline $\begin{array}{l}\text { Treatment* } \\
\text { flexible }\end{array}$ & & $\begin{array}{c}5.621^{* * * *} \\
(1.393)\end{array}$ & $\begin{array}{c}4.845^{* * *} \\
(1.569)\end{array}$ & - & $\begin{array}{c}5.824 * * * \\
(1.106)\end{array}$ & $\begin{array}{l}-0.101 \\
(0.070)\end{array}$ \\
\hline Price paid & - & - & $\begin{array}{c}0.879 * * * \\
(0.100)\end{array}$ & - & - & $\begin{array}{c}0.988^{* * *} \\
(0.005)\end{array}$ \\
\hline $\begin{array}{l}\text { Price paid* } \\
\text { flexible }\end{array}$ & - & - & $\begin{array}{l}-0.015 \\
(0.069)\end{array}$ & - & - & $\begin{array}{c}-0.0002 \\
(0.003)\end{array}$ \\
\hline $\begin{array}{c}\text { Price paid } \\
\text { squared }\end{array}$ & - & - & $\begin{array}{c}-0.019 * * * \\
(0.004)\end{array}$ & - & - & $\begin{array}{c}-0.0004^{* *} \\
(0.0002)\end{array}$ \\
\hline $\begin{array}{l}\text { Price paid* } \\
\text { cost shock }\end{array}$ & - & - & $\begin{array}{c}-0.017 * * * \\
(0.004)\end{array}$ & - & - & $\begin{array}{c}0.001 * * * \\
(0.0002)\end{array}$ \\
\hline Constant & $\begin{array}{c}10.676^{* * *} \\
(0.846)\end{array}$ & $\begin{array}{c}11.441^{* * *} \\
(0.896)\end{array}$ & $\begin{array}{c}6.149 * * * \\
(0.962)\end{array}$ & $\begin{array}{c}10.194 * * * \\
(0.687)\end{array}$ & $\begin{array}{c}10.949 * * * \\
(0.741)\end{array}$ & $\begin{array}{c}5.072 * * * \\
(0.049)\end{array}$ \\
\hline $\mathrm{N}$ & 879 & 879 & 879 & 879 & 879 & 879 \\
\hline $\mathrm{R}^{2}$ & 0.087 & 0.108 & 0.260 & 0.538 & 0.556 & 0.999 \\
\hline
\end{tabular}

Standard errors are in parentheses. $* * *, * *$, and $*$ indicate significance at $p=0.01, p=0.05$, and $p=0.10$ (two-tailed tests), respectively. Rigid contract $=0$, Flexible contract $=1$. Treatment $=0$ for the no-chat case and Treatment $=1$ with chat. We exclude the one case with an extreme buyer (seller) loss (gain). 
Figures 1-3: Patterns over time

Figure 1: Proportion of flexible contracts over time

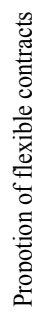

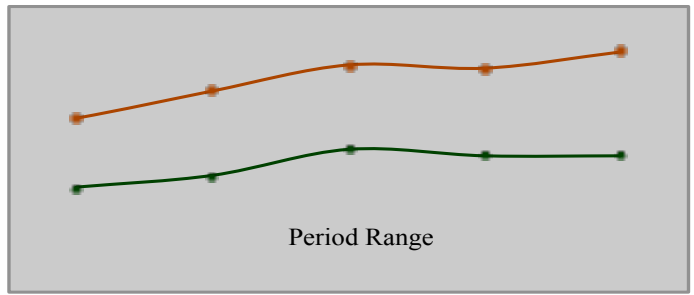

$\longrightarrow$ No comm
$\longrightarrow$ Chat

Figure 2: Average quality over time

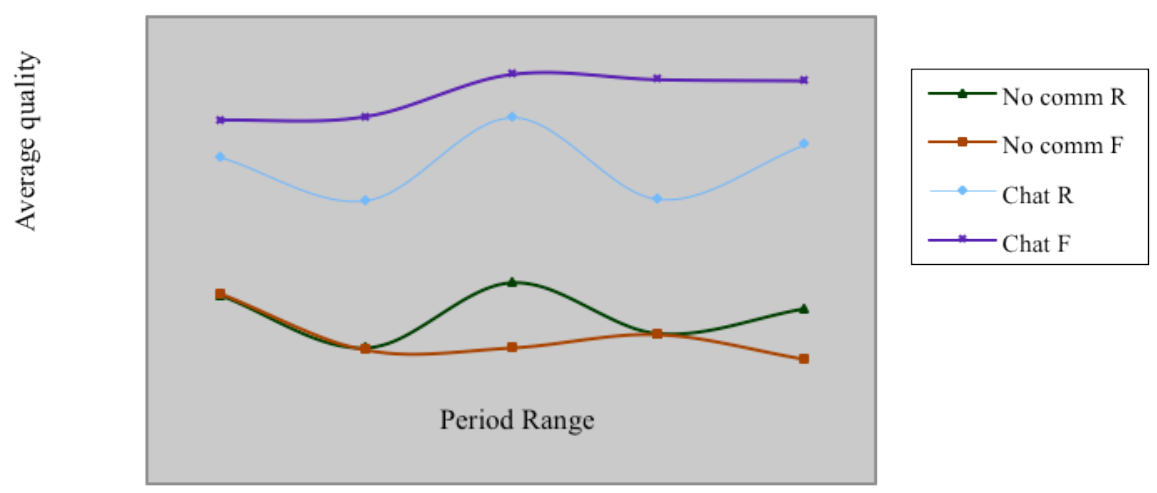

Figure 3: Average earnings over time

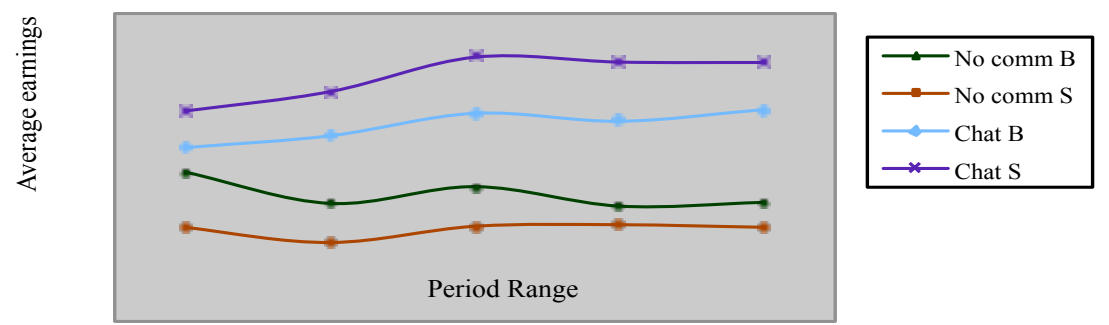




\section{Appendix A: Instructions}

(Notes to reader: the only difference between the chat and no-chat treatments is the presence of the paragraph on communication; we relabeled quality $x$ as response $\mathrm{R}$ to maintain neutrality.)

Thanks for coming to the experiment. You will receive 8 Euro for having shown up on time. In addition you will make money during the session.

The participants have been randomly divided into two roles - agents A and agents B according to the seat number. These roles will remain constant during the whole experiment.

The experiment will have 11 periods. In each period you will be matched with another person in the other role. This person will change from period to period and you will never be paired twice with the same person. At no point will you know with whom you are matched.

Each period is independent and develops as follows. Agent A and agent B each has an endowment of 5 monetary units and an opportunity to interact. To interact with B, A has to propose a contract type (I or II) and a transfer, P, and B must accept this; all this occurs before knowing whether B's cost is high (20) or low (0). After observing this cost (and if A and B agreed to interact), agent $\mathrm{A}$ can make an additional transfer, $\mathrm{Q}$, but only if the negotiated contract is of type II. If, by contrast, the negotiated contract is of type I, the transfer remains fixed at P. After observing the cost and agent A's final transfer ( $\mathrm{P}$ or $\mathrm{P}+\mathrm{Q})$, agent $\mathrm{B}$ chooses his/her response $\mathrm{R}$ between the values $-1,0$ and 1 , where $\mathrm{R}=-1$ or $\mathrm{R}=1$ imply an additional cost of 1 on $\mathrm{B}$ relative to $\mathrm{R}=0$. This response affects what agent $\mathrm{A}$ receives as explained below. In fuller detail, each period contains 5 stages:

- Stage 1: Agent A proposes to agent B:

a contract of type I with a non-negative transfer P(I)

$$
\text { --or-- }
$$

a contract of type II with a non-negative transfer of P(II) (the initial transfer)

- Stage 2: Agent B accepts or rejects this proposal.

If agent $B$ rejects, then the period ends without the following steps.

If agent $\mathrm{B}$ accepts, then the period proceeds to step 3 .

- Stage 3: The cost of agent B is randomly determined by the computer. With probability $1 / 2$ the cost is 0 and with probability $1 / 2$ the cost is 20 .

- Stage 4: If a contract of type II is agreed, then agent A can now increase the initial transfer with an additional non-negative transfer $\mathrm{Q}$ (that is, can make a total transfer of $\mathrm{P}+\mathrm{Q}$ instead of $\mathrm{P}$ ).

- $\quad$ Stage 5: Agent $\mathrm{B}$ chooses a response level $\mathrm{R}=-1, \mathrm{R}=0$ or $\mathrm{R}=1$.

At each stage, agent $\mathrm{A}$ and agent $\mathrm{B}$ are both directly informed of what happened in all earlier stages (of that period). 
At the end of a period, the results are as follows:

If agent $B$ rejects the contract proposed by agent $A$ :

Agent $\mathrm{A}$ and agent $\mathrm{B}$ each receive their initial endowment of 5 units.

If agent $B$ accepts:

Agent A receives: $15+0$ (if $\mathrm{R}=-1)+20$ (if $\mathrm{R}=0)+35$ (if $\mathrm{R}=1$ ) - transfer from $\mathrm{A}$ to $\mathrm{B}$.

Agent $B$ receives $5-\cos t-|R|+$ transfer from $A$ to $B$.

where the cost is $=0$ or 20 , depending of the outcome given by the computer, and the transfer from $\mathrm{A}$ to $\mathrm{B}=\mathrm{P}(\mathrm{I})$ if the contract is of type $\mathrm{I}$, and $=\mathrm{P}(\mathrm{II})+\mathrm{Q}$ if the contract if of type II.

After this we will proceed to the next period which will develop in the same way. Remember that you will never play the same person twice.

The first period, called period 0 , will be a trial period and will not be taken into account in determining what you will earn in the experiment. Periods 1 to 10 will not be trial periods. One of these will be randomly selected to determine what you earn in the experiment.

Each monetary unit is worth 1 Euro. At the end of the session you will be paid 8 Euros plus what you will have earned in the period that is selected randomly.

Communication: During each period, the agents A and B, can communicate through a chat. To do this, they have to write a message in the appropriate field and push "ENTER". Each participant A and B can close his/her chat window and can open it again after having closed it (all previous messages of the period will remain visible). While one participant has his chat window closed, he/she will not be able to read or send messages, but the participant he is matched with will continue to be able to send messages (which will be visible for the matched person once he/she reopens the chat window).

You can ask questions at any time. If you have a question, raise your hand and one of us will come to your cubicle to answer it.

Now we will briefly explain the screens that you will see once the experiment starts. 


\section{Appendix B: Session-level data}

Averages and frequencies are for all (offered) contracts, except with Q and quality (accepted contracts).

Table B1: Behavior in session 1 of the no-chat treatment

\begin{tabular}{|c|c|c|}
\hline Category & Rigid contract & Flexible contract \\
\hline Frequency* & $53(48.6 \%)$ & $56(51.4 \%)$ \\
\hline Rejections & $13(24.5 \%)$ & $13(23.2 \%)$ \\
\hline Average P & $15.15[1.00]$ & $13.00[0.83]$ \\
\hline Average Q & - & $2.44[0.58]$ \\
\hline Inferior quality & $10(25.0 \%)$ & $12(27.9 \%)$ \\
\hline Normal quality & $25(62.5 \%)$ & $30(69.8 \%)$ \\
\hline Superior quality & $5(12.5 \%)$ & $1(2.3 \%)$ \\
\hline Avg. buyer earnings (overall) & $12.08[1.41]$ & $11.00[1.20]$ \\
\hline Avg. seller earnings (overall) & $9.62[1.48]$ & $9.21[1.42]$ \\
\hline Avg. total earnings (overall) & $21.70[1.83]$ & $20.21[1.82]$ \\
\hline
\end{tabular}

* No contract was offered on one occasion. Standard errors are in brackets.

Table B2: Behavior in session 2 of the no-chat treatment

\begin{tabular}{|c|c|c|}
\hline Category & Rigid contract & Flexible contract \\
\hline Frequency* & $65(59.6 \%)$ & $44(40.4 \%)$ \\
\hline Rejections & $24(36.4 \%)$ & $26(59.1 \%)$ \\
\hline Average P & $14.09[0.62]$ & $10.00[0.55]$ \\
\hline Average Q & - & $1.78[0.83]$ \\
\hline Inferior quality & $14(34.1 \%)$ & $8(44.4 \%)$ \\
\hline Normal quality & $26(63.4 \%)$ & $10(55.6 \%)$ \\
\hline Superior quality & $1(2.4 \%)$ & $0(0.0 \%)$ \\
\hline Avg. buyer earnings (overall) & $9.78[1.08]$ & $8.55[1.32]$ \\
\hline Avg. seller earnings (overall) & $8.68[1.11]$ & $4.00[0.92]$ \\
\hline Avg. total earnings (overall) & $18.46[1.74]$ & $12.55[1.45]$ \\
\hline
\end{tabular}

* No contract was offered on one occasion. Standard errors are in brackets. 
Table B3: Behavior in session 3 of the no-chat treatment

\begin{tabular}{|c|c|c|}
\hline Category & Rigid contract & Flexible contract \\
\hline Frequency & $46(41.8 \%)$ & $64(58.2 \%)$ \\
\hline Rejections & $11(23.9 \%)$ & $15(23.4 \%)$ \\
\hline Average P & $12.93[0.88]$ & $10.66[0.48]$ \\
\hline Average Q & - & $2.78[0.44]$ \\
\hline Inferior quality & $9(25.7 \%)$ & $22(44.9 \%)$ \\
\hline Normal quality & $26(74.3 \%)$ & $26(53.1 \%)$ \\
\hline Superior quality & $0(0.0 \%)$ & $1(2.0 \%)$ \\
\hline Avg. buyer earnings (overall) & $12.61[1.35]$ & $10.34[1.19]$ \\
\hline Avg. seller earnings (overall) & $7.41[1.32]$ & $6.88[1.20]$ \\
\hline Avg. total earnings (overall) & $20.02[2.13]$ & $17.22[1.86]$ \\
\hline
\end{tabular}

Standard errors are in brackets.

Table B4: Behavior in session 4 of the no-chat treatment

\begin{tabular}{|c|c|c|}
\hline Category & Rigid contract & Flexible contract \\
\hline Frequency & $79(71.8 \%)^{\wedge}$ & $31(28.2 \%)^{\wedge}$ \\
\hline Rejections & $31(39.7 \%)$ & $11(35.5 \%)^{\wedge}$ \\
\hline Average P & $11.56[0.76]$ & $10.35[1.19]^{\wedge}$ \\
\hline Average Q & - & $3.45[0.72]^{\wedge}$ \\
\hline Inferior quality & $18(38.3 \%)$ & $11(35.5 \%)^{\wedge}$ \\
\hline Normal quality & $30(62.0 \%)$ & $7(22.6 \%)^{\wedge}$ \\
\hline Superior quality & $0(0.0 \%)$ & $2(6.4 \%)^{\wedge}$ \\
\hline Avg. buyer earnings (overall) & $9.72[0.94]$ & $7.84[1.28]^{\wedge}$ \\
\hline Avg. seller earnings (overall) & $6.13[0.94]$ & $7.23[1.89]^{\wedge}$ \\
\hline Avg. total earnings (overall) & $15.85[1.48]$ & $15.06[2.82]^{\wedge}$ \\
\hline
\end{tabular}

${ }^{\wedge}$ We exclude one case in which the buyer received a very large negative payoff in the final period. Standard errors are in brackets. 
Table B5: Behavior in session 1 of the chat treatment

\begin{tabular}{|c|c|c|}
\hline Category & Rigid contract & Flexible contract \\
\hline Frequency & $29(26.4 \%)$ & $81(73.6 \%)$ \\
\hline Rejections & $9(23.7 \%)$ & $4(4.7 \%)$ \\
\hline Average P & $19.41[1.76]$ & $17.37[0.84]$ \\
\hline Average Q & - & $9.29[0.86]$ \\
\hline Inferior quality & $6(30.0 \%)$ & $8(10.4 \%)$ \\
\hline Normal quality & $3(15.0 \%)$ & $15(19.5 \%)$ \\
\hline Superior quality & $11(55.0 \%)$ & $54(70.1 \%)$ \\
\hline Avg. buyer earnings (overall) & $10.83[0.58]$ & $15.59[1.45]$ \\
\hline Avg. seller earnings (overall) & $16.00[2.03]$ & $21.54[0.93]$ \\
\hline Avg. total earnings (overall) & $26.83[3.62]$ & $37.14[1.94]$ \\
\hline
\end{tabular}

Standard errors are in brackets.

Table B6: Behavior in session 2 of the chat treatment

\begin{tabular}{|c|c|c|}
\hline Category & Rigid contract & Flexible contract \\
\hline Frequency* & $12(11.1 \%)$ & $96(88.9 \%)$ \\
\hline Rejections & $6(50.0 \%)$ & $2(2.0 \%)$ \\
\hline Average P & $13.42[2.28]$ & $10.92[0.97]$ \\
\hline Average Q & - & $15.74[1.02]$ \\
\hline Inferior quality & $0(0.0 \%)$ & $5(5.3 \%)$ \\
\hline Normal quality & $4(66.7 \%)$ & $17(18.1 \%)$ \\
\hline Superior quality & $2(33.3 \%)$ & $72(76.6 \%)$ \\
\hline Avg. buyer earnings (overall) & $14.42[3.63]$ & $18.39[0.79]$ \\
\hline Avg. seller earnings (overall) & $7.92[3.78]$ & $20.81[0.95]$ \\
\hline Avg. total earnings (overall) & $22.33[4.51]$ & $39.20[1.44]$ \\
\hline
\end{tabular}

* No contract was offered on two occasions. Standard errors are in brackets. 
Table B7: Behavior in session 3 of the chat treatment

\begin{tabular}{|c|c|c|}
\hline Category & Rigid contract & Flexible contract \\
\hline Frequency & $53(48.2 \%)$ & $57(51.8 \%)$ \\
\hline Rejections & $3(5.7 \%)$ & $6(10.5 \%)$ \\
\hline Average P & $25.91[0.85]$ & $19.23[1.04]$ \\
\hline Average Q & - & $7.92[1.17]$ \\
\hline Inferior quality & $3(6.0 \%)$ & $4(7.8 \%)$ \\
\hline Normal quality & $21(42.0 \%)$ & $15(29.4 \%)$ \\
\hline Superior quality & $26(52.0 \%)$ & $32(62.8 \%)$ \\
\hline Avg. buyer earnings (overall) & $14.47[1.24]$ & $13.86[1.41]$ \\
\hline Avg. seller earnings (overall) & $18.94[1.69]$ & $19.19[1.23]$ \\
\hline Avg. total earnings (overall) & $33.42[2.37]$ & $33.05[2.19]$ \\
\hline
\end{tabular}

Standard errors are in brackets.

Table B8: Behavior in session 4 of the chat treatment

\begin{tabular}{|c|c|c|}
\hline Category & Rigid contract & Flexible contract \\
\hline Frequency & $17(15.4 \%)$ & $93(84.6 \%)$ \\
\hline Rejections & $2(11.8 \%)$ & $0(0.0 \%)$ \\
\hline Average P & $25.24[2.08]$ & $21.30[0.32]$ \\
\hline Average Q & - & $6.52[0.58]$ \\
\hline Inferior quality & $4(26.7 \%)$ & $3(3.2 \%)$ \\
\hline Normal quality & $5(33.3 \%)$ & $14(15.1 \%)$ \\
\hline Superior quality & $6(40.0 \%)$ & $76(81.7 \%)$ \\
\hline Avg. buyer earnings (overall) & $8.88[2.59]$ & $18.80[0.86]$ \\
\hline Avg. seller earnings (overall) & $17.00[1.16]$ & $21.65[2.80]$ \\
\hline Avg. total earnings (overall) & $25.88[4.39]$ & $40.44[1.27]$ \\
\hline
\end{tabular}

Standard errors are in brackets. 


\section{Appendix C: Chat categories, distribution, and correlations}

Table C1: Chat classifications and values (Offered contracts, overall)

\begin{tabular}{|c|c|c|c|c|c|}
\hline \multirow[t]{2}{*}{ Category } & \multicolumn{4}{|c|}{ Values and Frequency } & \multirow[t]{2}{*}{ Average value } \\
\hline & -1 & 0 & 1 & 2 & \\
\hline Q-Plan-Clarification & & 133 & 288 & & 0.684 \\
\hline Q-Discussion & & 314 & 107 & & 0.254 \\
\hline Influence by seller & & 206 & 54 & 160 & 0.652 \\
\hline Friendly & 38 & 199 & 184 & & 0.347 \\
\hline Fairness rigid contract (buyers) & & 406 & 15 & & 0.036 \\
\hline Fairness rigid contract (sellers) & & 407 & 14 & & 0.033 \\
\hline Fairness flexible contract (buyers) & & 277 & 144 & & 0.342 \\
\hline Fairness flexible contract (sellers) & & 319 & 102 & & 0.242 \\
\hline Cost-risk rigid contract (buyers) & & 414 & 7 & & 0.017 \\
\hline Cost-risk rigid contract (sellers) & & 388 & 33 & & 0.078 \\
\hline Cost-risk flexible contract (buyers) & & 413 & 8 & & 0.019 \\
\hline Cost-risk flexible contract (sellers) & & 394 & 27 & & 0.064 \\
\hline Pressure over $x$ & & 112 & 309 & & 0.734 \\
\hline Pressure over Q & & 238 & 183 & & 0.435 \\
\hline Promises over $x$ & & 234 & 187 & & 0.444 \\
\hline Promises over Q & & 385 & 36 & & 0.086 \\
\hline Impatience buyer & & 362 & 16 & 43 & 0.242 \\
\hline Impatience seller & & 353 & 22 & 46 & 0.271 \\
\hline Agreement & 58 & 97 & 266 & & 0.494 \\
\hline Unity & & 126 & 295 & & 0.701 \\
\hline Implicit disagreement & & 364 & 57 & & 0.135 \\
\hline Buyer fulfillment & 3 & 386 & 32 & & 0.069 \\
\hline Seller fulfillment & 38 & 234 & 149 & & 0.263 \\
\hline
\end{tabular}


Table C2: Chat classifications and values (Offered rigid contracts)

\begin{tabular}{|c|c|c|c|c|c|}
\hline \multirow[t]{2}{*}{ Category } & \multicolumn{4}{|c|}{ Values and Frequency } & \multirow[t]{2}{*}{ Average value } \\
\hline & -1 & 0 & 1 & 2 & \\
\hline Q-Plan-Clarification & & 90 & 11 & & 0.109 \\
\hline Q-Discussion & & 111 & 0 & & 0.000 \\
\hline Influence by seller & & 56 & 37 & 8 & 0.525 \\
\hline Friendly & 18 & 53 & 30 & & 0.119 \\
\hline Fairness rigid contract (buyers) & & 88 & 13 & & 0.129 \\
\hline Fairness rigid contract (sellers) & & 89 & 12 & & 0.119 \\
\hline Fairness flexible contract (buyers) & & 93 & 8 & & 0.079 \\
\hline Fairness flexible contract (sellers) & & 98 & 3 & & 0.030 \\
\hline Cost-risk rigid contract (buyers) & & 94 & 7 & & 0.069 \\
\hline Cost-risk rigid contract (sellers) & & 76 & 25 & & 0.248 \\
\hline Cost-risk flexible contract (buyers) & & 100 & 1 & & 0.010 \\
\hline Cost-risk flexible contract (sellers) & & 97 & 4 & & 0.040 \\
\hline Pressure over $x$ & & 42 & 59 & & 0.584 \\
\hline Pressure over Q & & 97 & 4 & & 0.040 \\
\hline Promises over $x$ & & 31 & 70 & & 0.307 \\
\hline Promises over Q & & 101 & 0 & & 0.000 \\
\hline Impatience buyer & & 92 & 3 & 6 & 0.149 \\
\hline Impatience seller & & 91 & 4 & 6 & 0.158 \\
\hline Agreement & 30 & 24 & 47 & & 0.168 \\
\hline Unity & & 46 & 55 & & 0.545 \\
\hline Implicit disagreement & & 75 & 26 & & 0.137 \\
\hline Buyer fulfillment & & 101 & & & 0.000 \\
\hline Seller fulfillment & 7 & 70 & 24 & & 0.168 \\
\hline
\end{tabular}


Table C3: Chat classifications and values (Offered flexible contracts)

\begin{tabular}{|c|c|c|c|c|c|}
\hline \multirow[t]{2}{*}{ Category } & \multicolumn{4}{|c|}{ Values and Frequency } & \multirow[t]{2}{*}{ Average value } \\
\hline & -1 & 0 & 1 & 2 & \\
\hline Q-Plan-Clarification & & 43 & 277 & & 0.866 \\
\hline Q-Discussion & & 217 & 107 & & 0.334 \\
\hline Influence by seller & & 150 & 17 & 152 & 1.006 \\
\hline Friendly & 20 & 146 & 154 & & 0.419 \\
\hline Fairness rigid contract (buyers) & & 318 & 2 & & 0.006 \\
\hline Fairness rigid contract (sellers) & & 318 & 2 & & 0.033 \\
\hline Fairness flexible contract (buyers) & & 184 & 136 & & 0.425 \\
\hline Fairness flexible contract (sellers) & & 221 & 99 & & 0.309 \\
\hline Cost-risk rigid contract (buyers) & & 320 & 0 & & 0.000 \\
\hline Cost-risk rigid contract (sellers) & & 312 & 8 & & 0.025 \\
\hline Cost-risk flexible contract (buyers) & & 313 & 7 & & 0.219 \\
\hline Cost-risk flexible contract (sellers) & & 297 & 23 & & 0.072 \\
\hline Pressure over $x$ & & 70 & 250 & & 0.781 \\
\hline Pressure over Q & & 141 & 179 & & 0.559 \\
\hline Promises over $x$ & & 164 & 156 & & 0.488 \\
\hline Promises over Q & & 284 & 36 & & 0.112 \\
\hline Impatience buyer & & 270 & 13 & 37 & 0.272 \\
\hline Impatience seller & & 262 & 18 & 40 & 0.306 \\
\hline Agreement & 28 & 73 & 219 & & 0.597 \\
\hline Unity & & 80 & 240 & & 0.750 \\
\hline Implicit disagreement & & 364 & 58 & & 0.137 \\
\hline Buyer fulfillment & 3 & 285 & 32 & & 0.091 \\
\hline Seller fulfillment & 31 & 164 & 125 & & 0.294 \\
\hline
\end{tabular}


Table C4: Correlations across chat categories

\begin{tabular}{|c|c|c|c|c|c|c|c|c|c|c|c|}
\hline & Q-clar & Q-disc & Influence & Friendly & Press_x & Press_Q & Agree & Unity & Disagree & Fulfill_B & Fulfill_S \\
\hline Q-clar & 1.000 & & & & & & & & & & \\
\hline Q-disc & \begin{tabular}{|l|}
-0.079 \\
$(0.610)$
\end{tabular} & 1.000 & & & & & & & & & \\
\hline Influence & $\begin{array}{c}0.229 \\
(0.135) \\
\end{array}$ & $\begin{array}{l}-0.104 \\
(0.501) \\
\end{array}$ & 1.000 & & & & & & & & \\
\hline Friendly & $\begin{array}{c}0.448 \\
(0.002)\end{array}$ & $\begin{array}{l}-0.012 \\
(0.939)\end{array}$ & $\begin{array}{c}0.436 \\
(0.003)\end{array}$ & 1.000 & & & & & & & \\
\hline Press_x & $\begin{array}{c}0.370 \\
(0.013)\end{array}$ & \begin{tabular}{|c|c|}
0.166 \\
$(0.283)$
\end{tabular} & $\begin{array}{c}0.260 \\
(0.089)\end{array}$ & \begin{tabular}{|c|}
$\mathbf{0 . 5 5 7}$ \\
$\mathbf{( 0 . 0 0 0 )}$
\end{tabular} & 1.000 & & & & & & \\
\hline Press_Q & \begin{tabular}{|c|}
0.371 \\
$(0.013)$ \\
\end{tabular} & \begin{tabular}{|c|}
0.096 \\
$(0.538)$ \\
\end{tabular} & $\begin{array}{c}0.472 \\
(0.001)\end{array}$ & \begin{tabular}{|c|}
0.362 \\
$(0.016)$ \\
\end{tabular} & $\begin{array}{c}0.262 \\
(0.085) \\
\end{array}$ & 1.000 & & & & & \\
\hline Agree & \begin{tabular}{|c|}
0.589 \\
$(0.000)$ \\
\end{tabular} & $\begin{array}{l}-0.092 \\
(0.550) \\
\end{array}$ & $\begin{array}{c}0.237 \\
(0.122) \\
\end{array}$ & \begin{tabular}{|c|}
0.782 \\
$(0.000)$ \\
\end{tabular} & $\begin{array}{c}\mathbf{0 . 6 3 6} \\
(\mathbf{0 . 0 0 0 )} \\
\end{array}$ & \begin{tabular}{|c|}
0.400 \\
$(0.007)$ \\
\end{tabular} & 1.000 & & & & \\
\hline Unity & $\begin{array}{c}0.452 \\
(0.002)\end{array}$ & \begin{tabular}{|c|}
0.328 \\
$(0.030)$
\end{tabular} & $\begin{array}{c}0.193 \\
(0.210)\end{array}$ & $\begin{array}{c}0.632 \\
(0.000) \\
\end{array}$ & $\begin{array}{c}\mathbf{0 . 5 1 7} \\
\mathbf{( 0 . 0 0 0 )} \\
\end{array}$ & \begin{tabular}{|c|}
0.047 \\
$(0.762)$
\end{tabular} & $\begin{array}{c}0.520 \\
(0.000)\end{array}$ & 1.000 & & & \\
\hline Disagree & $\begin{array}{l}-\mathbf{- 0 . 5 8 7} \\
(\mathbf{0 . 0 0 0 )}\end{array}$ & $\begin{array}{l}-0.085 \\
(0.582)\end{array}$ & $\begin{array}{l}-0.271 \\
(0.075)\end{array}$ & \begin{tabular}{|c}
$-\mathbf{- 0 . 7 8 9}$ \\
$(0.000)$ \\
\end{tabular} & $\begin{array}{l}\mathbf{- 0 . 6 0 7} \\
\mathbf{( 0 . 0 0 0 )} \\
\end{array}$ & \begin{tabular}{|c|}
-0.360 \\
$(0.016)$ \\
\end{tabular} & $\begin{array}{l}-\mathbf{0 . 8 4 1} \\
(0.000)\end{array}$ & $\begin{array}{l}-\mathbf{0 . 6 6 9} \\
(\mathbf{0 . 0 0 0 )}\end{array}$ & 1.000 & & \\
\hline Fulfill_B & \begin{tabular}{|c|}
0.288 \\
$(0.058)$ \\
\end{tabular} & \begin{tabular}{|c|}
0.149 \\
$(0.335)$ \\
\end{tabular} & $\begin{array}{l}-0.161 \\
(0.296) \\
\end{array}$ & \begin{tabular}{|l}
-0.017 \\
$(0.911)$ \\
\end{tabular} & $\begin{array}{c}0.352 \\
(0.019) \\
\end{array}$ & \begin{tabular}{|c|}
0.213 \\
$(0.165)$ \\
\end{tabular} & $\begin{array}{c}0.149 \\
(0.334) \\
\end{array}$ & $\begin{array}{c}0.229 \\
(0.135) \\
\end{array}$ & $\begin{array}{l}-0.220 \\
(0.152) \\
\end{array}$ & 1.000 & \\
\hline Fulfill_S & $\begin{array}{c}0.422 \\
(0.004)\end{array}$ & $\begin{array}{l}-0.228 \\
(0.136)\end{array}$ & $\begin{array}{c}0.262 \\
(0.086)\end{array}$ & \begin{tabular}{|c|}
0.373 \\
$(0.013)$ \\
\end{tabular} & $\begin{array}{c}\mathbf{0 . 3 8 4} \\
(\mathbf{0 . 0 1 0}) \\
\end{array}$ & $\begin{array}{c}0.308 \\
(0.042) \\
\end{array}$ & $\begin{array}{c}0.516 \\
(0.000) \\
\end{array}$ & $\begin{array}{c}0.371 \\
(0.013)\end{array}$ & $\begin{array}{l}-\mathbf{0 . 4 4 6} \\
(\mathbf{0 . 0 0 2})\end{array}$ & $\begin{array}{c}0.167 \\
(0.278) \\
\end{array}$ & 1.000 \\
\hline
\end{tabular}

The top number in each cell represents the correlation coefficient between the row and the column. Two-tailed $p$-values are below, in parentheses.

This correlation table was constructed by considering each individual and constructing a measure of how often he or she uses the unit value of that chat category, in the binary 0-1 case (and more generally, the average value of that chat variable) and then taking all individuals and looking at the pairwise correlations.

Q-clar means Q-clarification, Q-disc means Q-discussion, Influence means influence by seller, Press_x means pressure over quality, Press_Q means pressure over Q, Fulfill_B means fulfillment by buyer, and Fulfill_S means fulfillment by seller. 


\section{Appendix D}

- Q-Clarification: Does B or $S$ mention any value or values of $Q$ before they learn the cost $C$ ? Code as: 0,1 .

- $\quad$ Q-Discussion: Do $B$ and/or $S$ discuss what value of $Q$ should be set by $B$ after they observe if the cost $C$ is 20 or 0 ? Code as: 0,1 .

- Q-values: If any, what are the main values of QH-plan and QL-plan and DQ-plan=QH-plan - QL-plan (the difference in value) that B promises or $S$ suggests (and B does not explicitly reject) in the chat before $B$ and $S$ learn the cost $C$ ? Code as QH-plan=-1 if negative or code as positive number, code as QL-plan=-1 if negative, or code a positive number, code as DQplan $=-1$ if negative or code as positive number.

- S's-Type-preference: Does $S$ influence B toward choosing a rigid contract or a flexible contract? Code as: 0,1,2.

- $\quad$ Friendly: Is the conversation friendly/cordial/respectful/humorous? Code as: -1,0,1

- $\quad$ Fairness \& Contract-Type: Does either (B or $S)$ refer to fairness as a reason for choosing a rigid or a flexible contract? Code as: 0,1 .

- Cost-risk \& Contract-Type: Does either (B or $S$ ) refer to the cost risk as a pain (or the value of insurance or sharing risk) as a reason for choosing a rigid contract or a flexible contract? Code as: 0,1 .

- Pressure over $\mathbf{x}$ : Does $B$ put any kind of pressure on $S$ to set $x=1$ or at least to not set $x=-1$ ? Code as: 0,1 .

- $\quad$ Pressure over Q: Does $S$ put any kind of pressure on B to set a positive value of $Q$ (or fulfil a promise over Q)? Code as: 0,1 .

- $\quad$ Promise over $\mathbf{x}$ : Does $S$ in any sense promise or ask $B$ to trust him/her to set $x=1$ (or $x=0)$ ? Code as: 0,1 .

- $\quad$ Promise over Q: Does $B$ in any sense promise or ask $S$ to trust him/her to set some specific or positive values of $Q$ ? Code as: 0,1 .

- Impatience of A: Does B show impatience with $S$ or with external causes of delay or no impatience shown? Code as: 0,1,2.

- $\quad$ Impatience of B: Does $S$ show impatience with B or with external causes of delay or no impatience shown? Code as: 0,1,2.

- $\quad$ Agreement: Do B and S roughly agree or is there some notable conflict? Code as: -1,0,1.

- Unity: Does either (B or $S$ ) use the first-person plural to refer to self and current partner? Code as: 0,1 .

- Implicit disagreement: Does $B$ set a $P$ or a $Q$ below $S$ 's final request? Code as: 0,1 .

- $\quad$ Fulfillment by A: Does $B$ fulfill any promise (over $Q$ )? Code as: $-1,0,1$.

- $\quad$ Fulfillment by B: Does $S$ fulfill any promise (over $x$ )? Code as: $-1,0,1$. 